\title{
الفاعل الجمعياتي ومكافحة الفقر في موريتانيا
}

\section{The Civil Society Organizations and Combatting Poverty in Mauritania}

تتناول هذه الدراسة موضوع الفقر والفاعل الجمعياتي في موريتانيا، من خلال رصدٍ وتحليلٍ للأدوار التهي

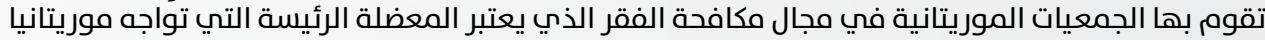

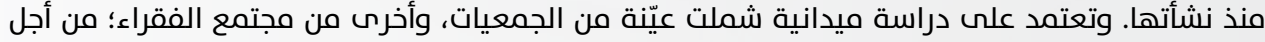

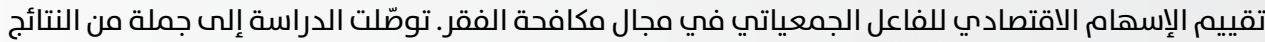

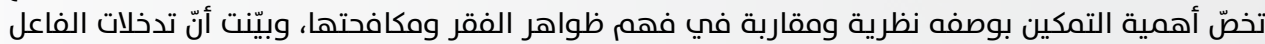

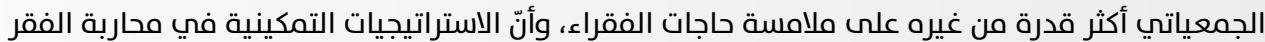

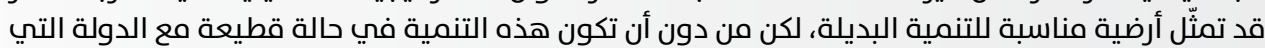

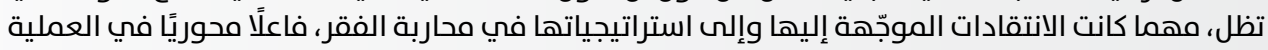

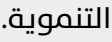

كلمات مفتاحية: موريتانيا، التمكين، مكافحة الفقر، المنظمات غير الحكومية، المجتمع المدني.

This study examines the issue of poverty and civil society organizations in Mauritania analyzing the roles these organizations play in fighting poverty, considered to be the primary dilemma facing Mauritania since it was established. This research is based upon a field study, comprising a sample of organizations as well as a sample of the impoverished population, so as to evaluate the economic contribution of civil society actors in combatting poverty. The study arrives at a set of conclusions relating to the importance of empowerment in understanding the manifestations of poverty and the ways it can be eliminated. Field research results further suggest that interventions by the civil society actor are more effective than those of others in addressing the needs of the impoverished. Moreover, the study concludes by highlighting the important role of the state in the development process and the idea that the civil society organizations' role is not to be a substitute for government.

Keywords: Mauritania, Empowerment, Combatting Poverty, NGOs, Civil Society.

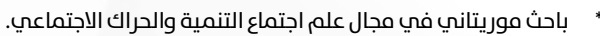
Mauritanian Researcher in sociology of development \& social Mobility. 
"إن مأزق موريتانيا الكبير ومشكلتها الكبيرة التي تتطلب حلًا سريعًا وعميقًا هي مشكلة الفقر"(1)

\section{مقدمة}

يُعدّ الفقر التحدي الأبرز لموريتانيا منذ نشأتها حتى اليوم، فعلى الرغم من مرور أكثر من ستة عقود على استقلالها،

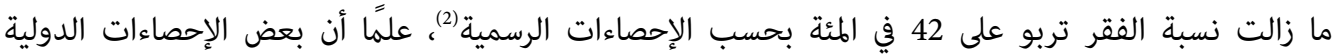
والإقليمية تتحدث عن نسبة تتجاوز 70 في المئة (3). ويعود هذا التضارب في الأرقام إلى اختلاف المؤشرات المعتمدة الماتية في قياس الفقر بين الحكومة الموريتانية والجهات الأخرى الإقليمية والدولية، ولعل نسبة البطالة بين السكان، التي تصل بحسب الإحصاءات الرسمية إلى 30 في المئة (4)، ونسبة الشعور بالفقر لدى المواطنين، التي تصل في آخر مسح الخح

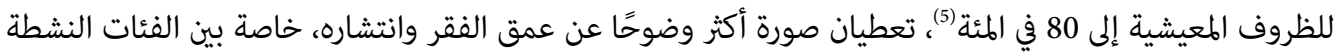
في المجتمع، وأهمها الشباب. ويدل هذا الواقع على وجود جملة من الأعطاب في السياسات الاقتصادية والاجتماعية التي راهنت عليها الدولة الوطنية في مكافحة الفقر، وتحريك عجلة التنمية في البلاد.

اقتضت هذه الوضعية دخول فاعلين جدد على خط مكافحة الفقر، وكان الفاعل الجمعياتي، في صيغته الأهلية

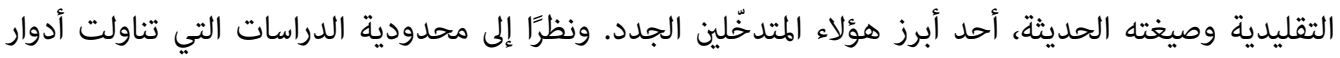

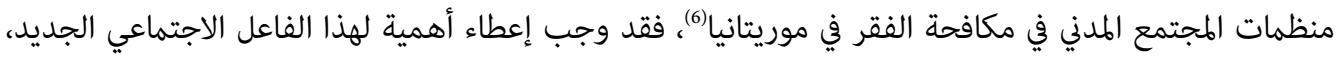

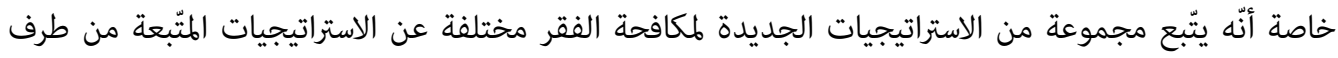
الحكومات التي تتسم بالعمومية، ونادرًا ما تلامس الاحتياجات الدقيقة لطجتمع الفقراء. وبناءً على ذلك، تتبنى الدراسة منظورًا يعتبر النشاط أو الفعل الجمعياتي وجهًا من أوجه الفعل الاجتماعي والنشاط

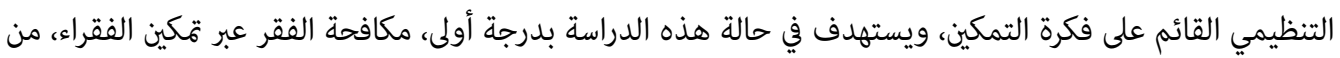
خلال مجموعة من الاستراتيجيات والتدخلات المتنوعة. ومن هذا المنطلق، تحاول الدراسة الإجابة عن سؤال مركزي هو: إلى

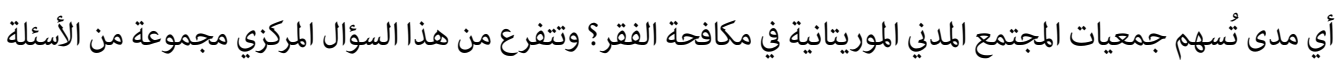

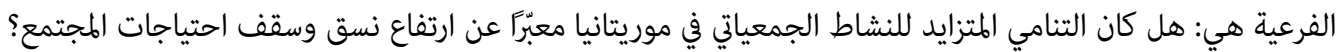
وكيف تطوّر هذا النشاط؟ وهل يمكن أن نتحدث عن إسهام اقتصادي واجتماعي لجمعيات المجتمع المدني الموريتانية؟ لمقاربة هذه الأسئلة، تُّت هيكلة الدراسة على نحو يُلبّي مقتضيات التناول العلمي لظاهرة تفاعل الجمعيات موضوع

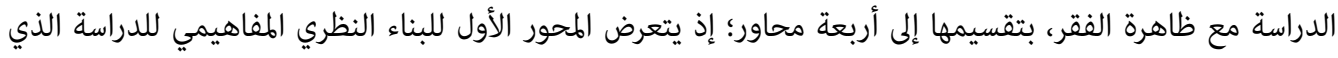

1 Pierre Bonte, "Lévolution de la société rurale Mauritanienne: Le pari de la sécurité alimentaire," Politique Africaine, no. 55 (Octobre 1994), p. 78. 2 2 2 3 لغربي آسيا - الإسكوا، 2017)، ص 16-23. 4 4 5

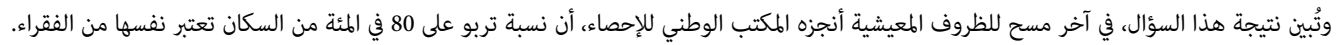

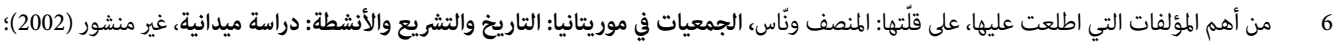
منّينة عبد الله، التقرير السنوي الأول: نشاط المنظمات الأهلية في الجمهورية الإسلامية الموريتانية (القاهرة: الشبكة العربية للمنظمات الأهلية، 2002). 
يكن اعتباره بمنزلة فوذج التحليل الذي اختاره الباحث، ثم يقدم المحور الثاني خلفية عن واقع الفقر في موريتانيا، وتجاوب الفاعل الرسمي الممثل في الدولة معه. أما المحور الثالث، فيتطرق بالتحليل إلى منهجية تناول إسهام الجمعيات

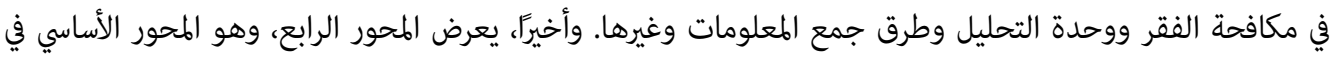
هذه الدراسة، لتدخلات الجمعيات ومقاربتها الخاصة للفقر وتمثلات عيّنة الفقراء لهذا التدخل خصوصًا، وللفقر عمومًا. تنطلق هذه الدراسة من فرضية تعتبر الفقر حرمانًا من التمكين، وأنّ الاستراتيجيات المتبعة من طرف المجتمع المدني

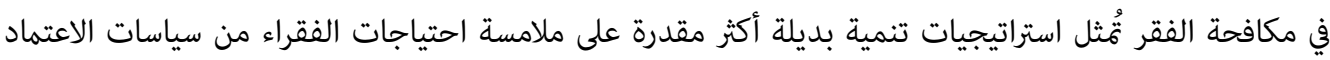

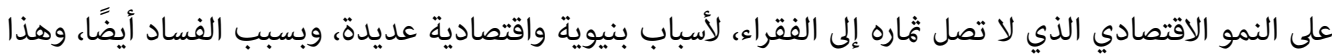

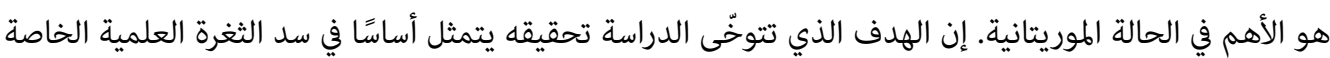
بتناول أدوار الجمعيات في موريتانيا، ورصد مدى فاعليتها في مواجهة ظاهرة معقّدة مثل ظاهرة الفقر.

\section{أولًا: إطار مفاهيمي ونظري}

حظي موضوع الفقر باهتمام كبير من طرف علماء الاجتماع والاقتصاد، وانعكس ذلك في غزارة المقاربات النظرية

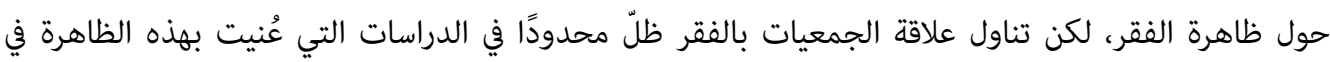

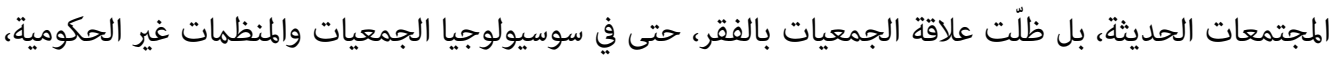
وهو حقل معرفي جديد، موضوعًا هامشيًا، على الرغم من أن مكافحة الفقر تعد من أبرز الأدوار التي يقوم بها

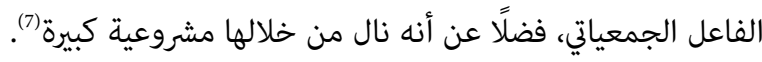

1. مفهوم الفقر

للإحاطة بما يشبه فهماً متكاملًا للفقر، لا بد من التطرق إلى أبرز المقاربات والتفسيرات التي فسّرت هذه الظاهرة. وفي هذا الشأن، هناك نظان من التفسيرات. ويكن أن نطلق على الأول التفسير الاجتماعي للفقر، وعلى الآخر التفسير الاقتصادي المادي للفقر. الفقر في المنظور السوسيولوجي متنوع ومتعدد، ومن التعسف تعميم محدِّدٍ واحد، كالمحدد الاقتصادي مثلاً، لتفسيره وقياسه، مع إهمال خصوصيات المجتمعات ووضعياتها التاريخية والراهنة؛ فالفقر مظاهر ومستويات. وبناءً عليه، لا ينبغي أن يتأسّس مفهومنا للفقر على التعميم وحده، وإفا ينبغي أن يتأسس أيضًا على التخصيص المستند

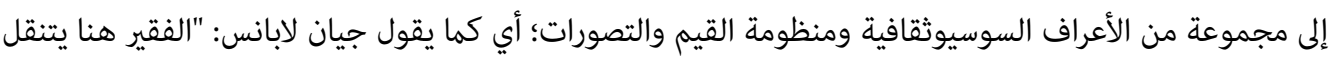

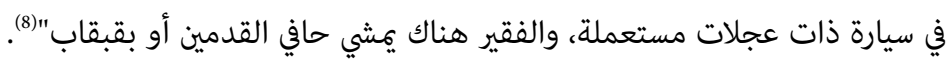

والمنحى نفسه أكّده عالم الاجتماع الإنكليزي بيتر تاونسند Peter Townsend، عندما ربط الفقر بالعادات الخاصة

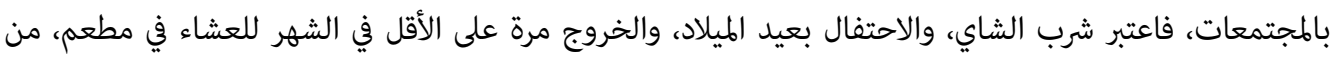

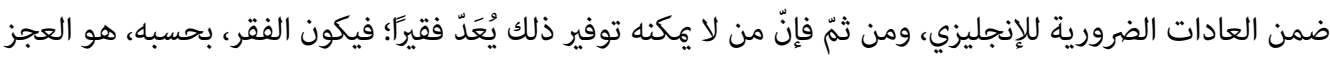

7 ا المنصف ونّاس، الحياة الجمعياتية في المغرب العربي: التاريخ والواقع والآفاق: الجزائر، المغرب الأقصى، تونس (تونس: ألتالير، 1997)، ص 45. 
عن عدم تمتع الناس بالمستوى الأساسي المتعارف عليه من الغذاء، وظروف المعيشة، وأنشطة الفراغ، وأسباب الراحة

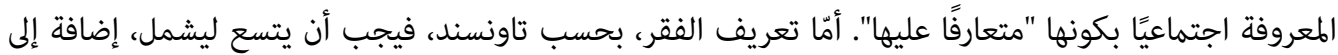

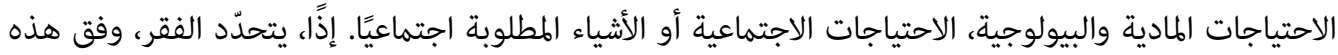

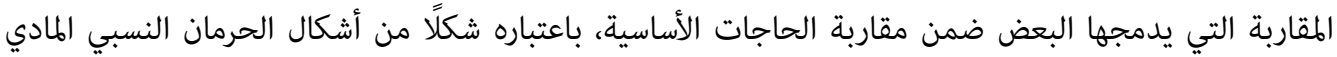
والاجتماعي (9). ولا يرتكز الرهان، في مثل هذه المقاربات لكافحة الفقر، على النمو الاقتصادي، وإفا على استراتيجيات

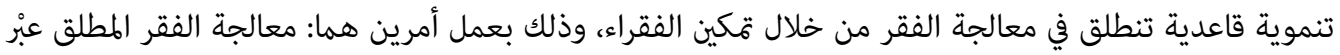

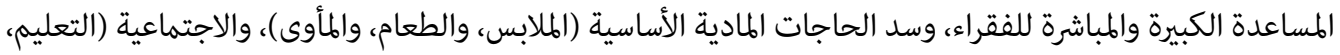
والحقوق الإنسانية، أو ما يسمى المشاركة في الحياة الاجتماعية من خلال العمل والالتزام السياسي والجمعياتي)(10). إلى جانب هذه المقاربة، توجد مقاربة أخرى تدور حول مفهوم "ثقافة الفقر"، وهي مقاربة تعتبر الفقراء مسؤولين،

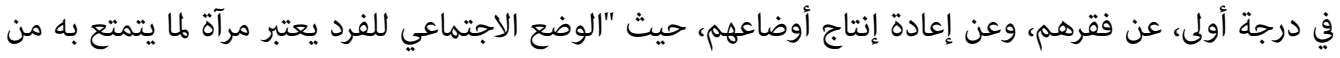

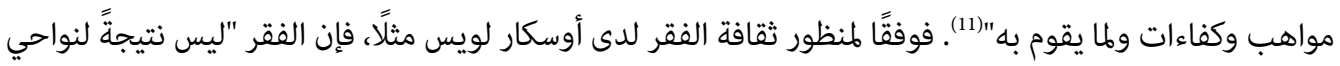
القصور والعجز الفردية، بل هو حصيلة لبيئة اجتماعية ثقافية واسعة تجري فيها التنشئة الاجتماعية للأطفال،

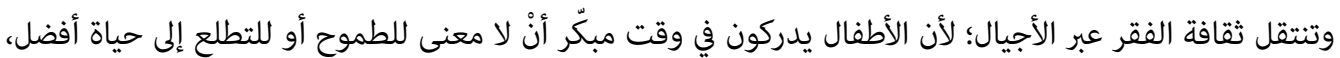

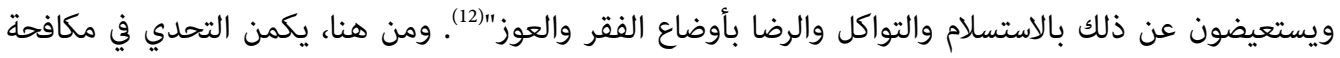
الفقر في محاربة ثقافة الفقر التي تعتبر إزالتها أصعب من إزالة الفقر نفسه.

وعلى الرغم من أن لويس بنى استنتاجاته تلك من خلال دراسات ميدانية، فإن نظريته كانت محط العديد من

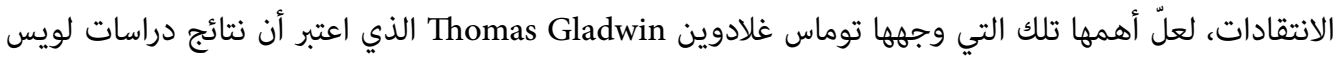
حول فقراء المدن المكسيكية لا تنطبق على كل فقراء المدن، ثمّ إنّ السمات التي اعتبرها لويس خصائص لثقافة الفقر

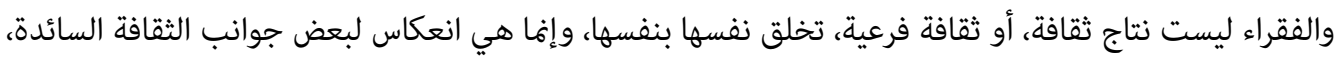

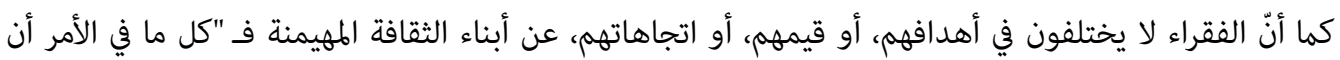

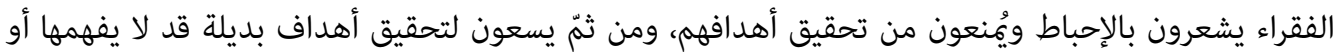

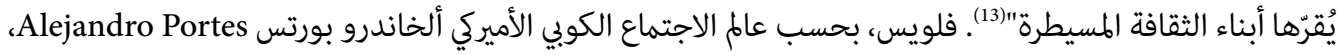
ينظر إلى التكيف الانتقالي المؤقت مع الظروف الصعبة التي تكتنف الحياة الحضرية الصعبة على أنها سلوك مقنّن، وبذلك يكون مفهوم ثقافة الفقر مجرّد وسيلة تعمل على زيادة السلبية السياسية تجاه الفقراءلمان. وقد كان هذا النقد مدخلًا نحو تبلور مقاربة بنيوية تشدّد على العمليات الاجتماعية العريضة التي تنتج الفقر ويتعذر

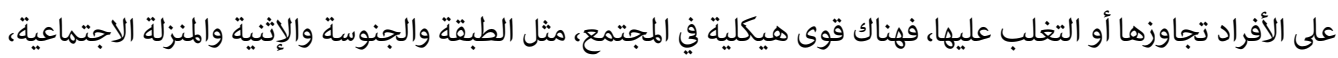
9 أندرو ويبستر، مدخل لسوسيولوجية التنمية، ترجمة حمدي حميد يوسف، سلسلة المائة كتاب (بغداد: دار الشؤون الثقافية العامة، 1986)، ص 28.

10

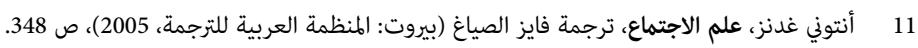

12 Oscar Lewis, Five Families: Mexican Case Studies in the Culture of Poverty (New York: Basic Books, 1959).

13 إسماعيل قيرة، "من هم فقراء الحضر؟ قاع المدينة العربية نهوذجًا"، المستقبل العربي، العدد 205 (آذار/ مارس 1996)، ص 81. 
تشكل أسلوب توزيع الموارد. ومن ثم، فإن تخفيف الفقر - وفق هذه المقاربة - لا يعتمد على تغيير توجهات الناس ونظرتهم إلى الحياة، بل على وضع السياسات الهادفة إلى توزيع الدخل والموارد بصفة أكثر إنصافًا في المجتمع. أما التفسير المادي للفقر، أو الفقر البيروقراطي، فينطلق من أرضية اقتصادية وإحصائية بحتة، تُحدد الفقر عبر متغيرات مادية صارمة، تتمثل أساسًا في متغير الدخل اليومي أو السنوي، إضافة إلى متغيرات مكمّلة على غرار مؤشر الاستهلاك الكيّك

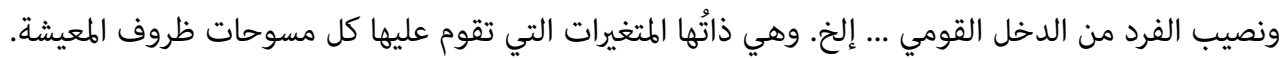
يرتبط هذا المنظور الإحصائي أو المادي للفقر بهجموعة مفاهيم إجرائية طوّرتها بيروقراطية الدولة، وأصبحت حاليًا قتثّل جزءًا من المفردات التنميطية والطعيارية للفقر، ومن بينها على سبيل المثال لا الحصر: مفهوم خط الفقر، وخطٌ الفقر المطلق، وخطّ الفقر النسبي، وشدة الفقر، وفجوة الفقر، وجيوب الفقر، ومفهوم السكان المستهدفين ... إلخ. ويسمّي جون فريدمان John Friedmann خطاطة هذه المفاهيم الفقرَ البيروقراطي bureaucratic poverty، وهو مفهوم نقدي يعني به "الفقر الذي يتم تعريفه من غير الفقراء، بل ممن يعتبرون أنفسهم متفوقين على الفقراء اجتماعيًا"(15). فالفقر، بحسب فريدمان، يعني "حالة من عدم التمكين النسبي فيما يتعلق بوصول الأسرة إلى أسس محددة من من القوة الاجتماعية، ولذلك فإن التمكين الاجتماعي والسياسي للفقراء، هو مفتاح التغلب على الفقر الجماعي"(16.). بناءً على ما سبق، في الإمكان أن نعمد إلى وضع مفهوم إجرائي للفقر يحدد أبعاد الفقر والمؤشرات الخاصة بكل بعد على حدة، استنادًا إلى التفسيرات السابقة، إذ يعتبر الدخل المنخفض وانعدام المات المدّخرات والعجز عن تلبية الاحتياجات

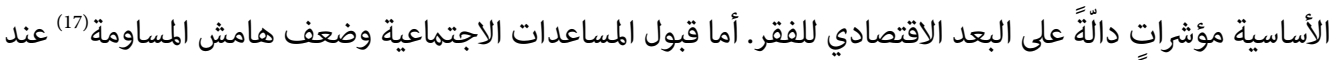
الفقراء وضعف المشاركة والأمية والوعي السلبي بأوضاع البؤس الاجتماعي، فهي مؤشرات دالّة على البعد الاجتماعي

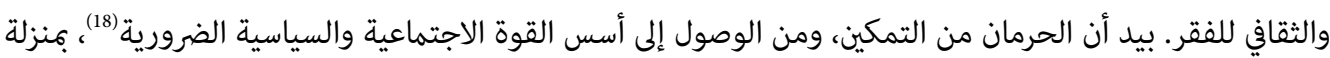
البعد الشامل للفقر. وبناءً على ذلك، فإن الفقر ظاهرة متعددة الأبعاد، ولا ترمز إلى مجرد نقص الدخل فقط لئل

2. مفهوم التمكين عرّف فريدمان الفقر باعتباره حالة من عدم التمكين النسبي(20)، وكان الهدف من هذا التعريف تجاوز التعريف

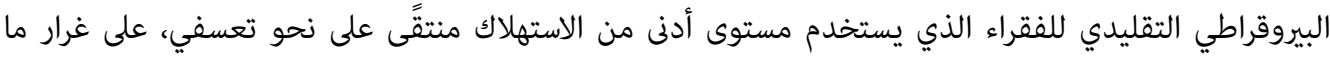

$$
15 \text { } 16 \text { جون } 16
$$

17 أمر 17

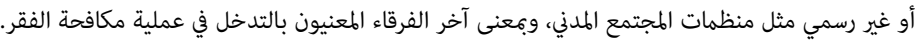
18

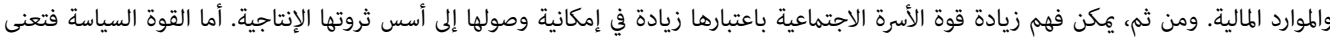

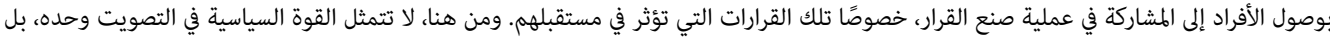

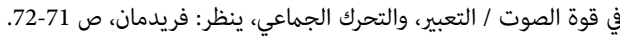
19 119 20 
نلاحظه عادة في التعريفات الاقتصادية والإحصائية التي تهدف إلى التعميم، وتُهمل في سبيل ذلك الأبعاد غير المرئية، أو التي لا يكن إحصاؤها وتكميمها في معيش الفقراء.

لقد كان هذا النقد ممنزلة بوابة لطرح فكرة التنمية البديلة القائمة على منطلقات مختلفة عن منطلقات فلسفة النمو

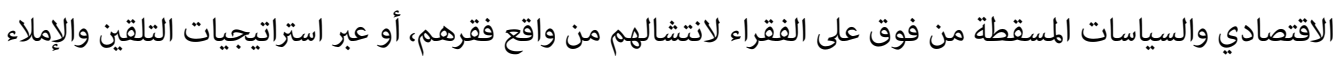

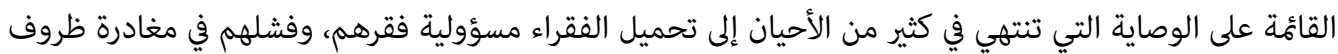
العوز والخصاصة، في انسجام كامل مع مقاربة ثقافة الفقر.

في هذا السياق النقدي يتنزل مفهوم التمكين الذي يُثمّن ملكات وقدرات الفقراء باعتبارهم ذواتًا فاعلة تمتلك القدرات والمؤهلات البشرية الضرورية للتغلب على ظروف الفقر، شريطة مُكينهم من الوسائل (21). يرتبط مفهوم التمكين ارتباطًا وثيقًا بأسس القوة الاجتماعية في أي مجتمع (22.) وبعض أسس هذه القوة، كما هو

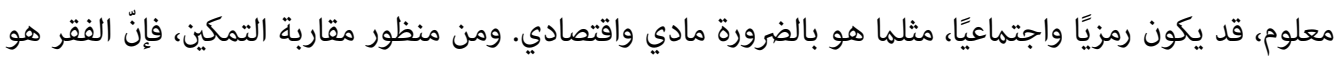

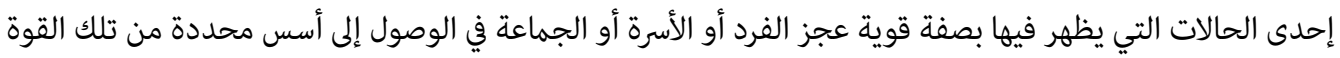

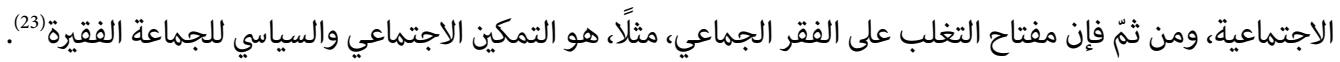

وبناءً على ذلك، يمكن القول إن الحرمان من التمكين ينطوي على أبعاد عدة اجتماعية وسياسية واستراتيجية.

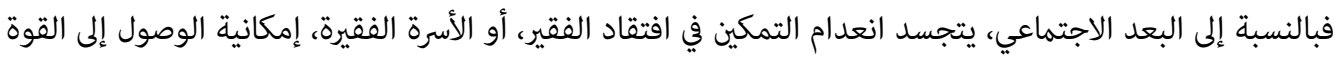
الاجتماعية الضرورية لتحسين ظروف المعيشة، وإشباع الحاجات الاجتماعية والاقتصادية (الموارد المالية، والمعرفة،

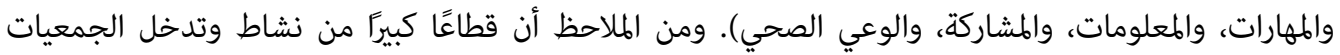

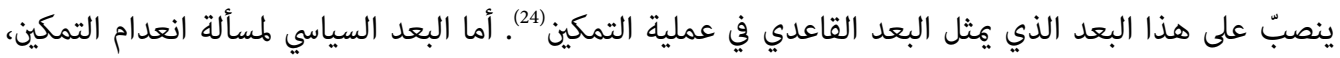

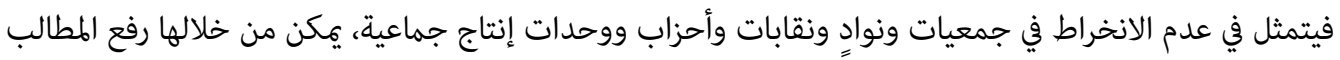

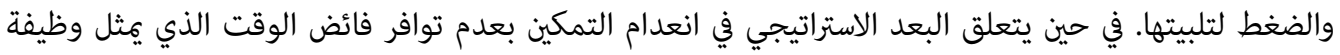
لأشياء كثيرة، ومن دونه تكون خيارات الفقراء مقيدة تقييدًا شديدًا في تحسين وسائل العمل وسبل العيش.

من وجهة نظرنا، تمثل هذه الأبعاد مجتمعة المفهوم الإجرائي للتمكين الذي تُراهن عليه الدراسة، ويمثل محور تركيز

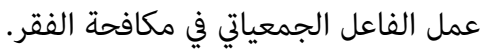

\section{3. مفهوم الفاعل الجمعياتي}

إنّ مفهوم الفاعل الجمعياتي من المفاهيم المركّة التي تحتاج إلى تدقيق مفهومي في سياق دراستنا، ونعني به هنا جمعيات

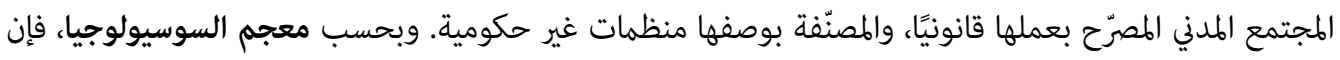

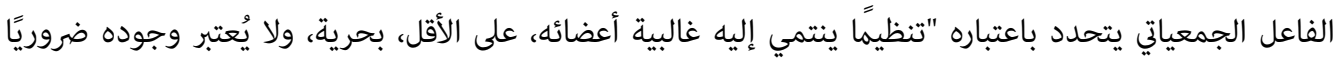

21 Houda Laroussi, Micro-crédit et lien social en Tunisie: La solidarité instituée (Tunis: IRMC; Paris: Karthala, 2009), p. 97.

22 Ridha Boukraa, Comprendre la mondialisation: Études sociologiques (Tunis: Centre de Publication Universitaire, 2005), p. 64.

24 Laroussi, p. 161. 
لحياة المجتمع ضرورة مطلقة"(25). لكن تجدر الإشارة إلى أن تأسيس الجمعيات لا يمثل ترفًا، بل بات يمثل ضرورة اجتماعية، وذلك لأن الجمعيات تملأ الفراغ الذي تتركه عادة تدخلات الفاعل العمومي أو الرسمي، أو نتيجة لمحدودية تلك التدخلات أمام الطلب المتزايد. وفي التقليد السوسيولوجي القديم نسبيًا، كانت الجمعية، وفقًا لتعريف ألكسيس التهاب دو توكفيل Alexis de Tocqueville (1805-1859)، على سبيل المثال، تعني: "تعاونًا بين مجموعة من الناس بغضّ النظر عن الاختلافات القائة بينهم على مستوى السن والعقلية والثروة [...] إنها تقرب بينهم وتخلق اتصالًا بينهم، وتُعلّمهم كيف يجعلون إرادتهم في خدمة إرادة الآخرين، وجغْل جهودهم الخاصة في خدمة الصالح العام"(26). ويؤكد هذا التعريف البعدين الأخلاقي والاجتماعي للعمل الجمعياتي بوصفه عملًا تطوعيًا لصالح خدمة المجتمع يتجاوز الذات إلى الغير، بيد أن العمل الجمعياتي الراهن يضيف بعدًا آخر إلى البعدين السابقين هو البعد الاقتصادي، من خلال قيادة مشاريع تنموية مندمجة في المناطق الفقيرة، ومُساعِدٍٍ على خلق أنشطة مدرّة للدخل لفائدة فئات هشة، وخلق مناصب شغل لبعض العاطلين عن العمل، والطساهمة في الناتج المحلي الخام (27). فضلًا عن هذا المستوى من التحديد، فإنّ كلًّ من الفاعل الجمعياتي أو الفاعل غير الرسمي قد يشير إلى ما هو عام أو إلى ما هو خاص ونوعي؛ من قبيل جمعية حي، أو منظمة ثقافية ورياضية، أو جمعية تنمية، أو جمعية معوقين؛ ما جعل بعض الدراسات تتحدث عن تعدد منطق ومجال الفعل الجمعياتي؛ إذ يمكن إدراك الفاعل الجمعياتي أو الفاعل غير

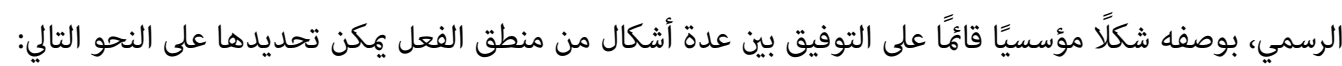

† منطق تجاري مرتبط بالسوق بوصفه آلية تضمن استقرار المصالح المتضاربة وتوازنها. | - منطق يقوم على الثقة.

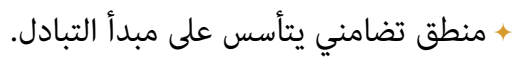
+ منطق إداري يُحيل على مبادئ الصالح العام(28). إذًا إنّ مفهوم الفاعل الجمعياتي مفهوم مركّب يحيل على مستويات متعددة. فعلى مستوى التعريف الوظيفي، يكن القول إنه القطاع الأهلي أو القطاع الثالث، ويشير هذا التعريف إلى تبادل المصالح بين مجموعة من الناس لتحقيق نفع مهري عام. أمّا التعريف القانوني، فيحصر تعريف الفاعل الجمعياتي في صفته المميزة بوصفه قطاعًا غير ربحي، بينما يؤكد التعريف الاقتصادي والمالي أنه يتمثل في القطاع الخيري أو الوقفي، وبتعبير آخر الاقتصاد الاجتماعي والتضامني. ويركز هذا التعريف على مصدر التمويل المتأتيّ من هبات واشتراكات، وكذلك من بيع سلع وخدمات. أما التعريف الهيكلي، فيعتبر أن الفاعل الجمعياتي هو القطاع المستقل، أو القطاع التطوعي غير الحكومي. ويستند هذا التعريف إلى مجموعة من الملامح والخصائص المتمثلة في الاستقلالية، والتطوع، والإدارة الذاتية، وعدم توزيع الأرباح على الأعضاء. 


\section{ثانيًا: خلفية عن واقع الفقر في موريتانيا: حجم المشكل وتجاوب الدولة}

\section{1. مشكلة الفقر}

تغطّي الصحراء ثلاثة أرباع مساحة موريتانيا. وإلى حدود السبعينيات، مل تكن نسبة السكان الحضريين تتجاوز 7 في

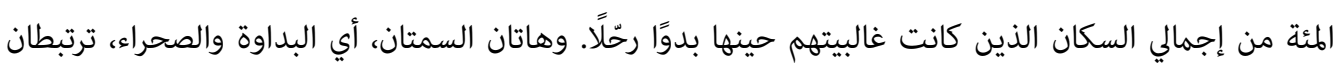

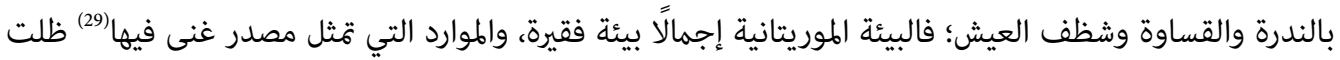
إلى عهد قريب مجهولة بالنسبة إلى الموريتانيين.

منذ دخول الاستعمار الفرنسي إلى التراب الموريتاني سنة 1902، والبلد يشهد - بوتيرة متزايدة - عمليات إفقار واسعة للمجتمع، سواء عن طريق الضرائب المجحفة، أو عن طريق نهب الثروات المعدنية (30). وعلى الرغم من أن دولة الاستقلال مثّلت فرصة لوقف نزيف استغلال الثروات الوطنية والشروع في عملية بناء وطني شامل، فإن جلّ سياساتها الاقتصادية والاجتماعية أخفقت في تحقيق التنمية المنشودة، بالنظر إلى عوامل عديدة نذكر منها على سبيل المثال لا الحصر ما يلي (31):

$$
\text { \$ عدم ملاءمة السياسات الاجتماعية والاقتصادية لطبيعة الاقتصاد الموريتاني. }
$$

ه الصراعات السياسية المبكرة التي اتخذت في بعض الأحيان طابع صراع هوياتي بين مكونات زنجية أفريقية

$$
\text { ومكونات عربية صنهاجية. }
$$

ه العشوائية في البرامج والخطط التنموية، بسبب الارتباك الناجم عن الجفاف الكبير الذي ضرب موريتانيا في مطلع السبعينيات، واستمر حتى منتصف الثمانينيات، وقد أدّى ذلك إلى نفوق الثروة الحيوانية التي كانت تثثل عصب اقتصاد الريف، حيث كانت تقطن غالبية السكان؛ ما تسبب في موجات هجرة كثيفة أثقلت

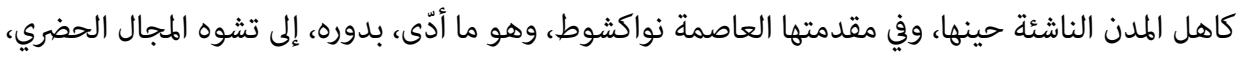

$$
\text { وتشكل ظاهرة الفقر الحضري الواسع النطاق. }
$$

ه الفساد الذي نخر مؤسسات الدولة(32) منذ فترة ما بعد انقلاب العاشر من تموز/ يوليو 1978، وسيطرة

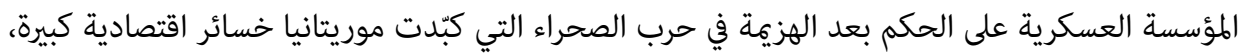

29 المقصود أساسًا البحر بثرواته السمكية إضافة إلى الثروة المعدنية.

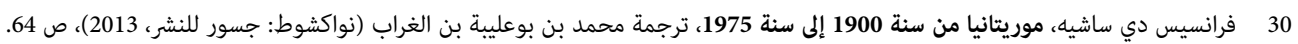

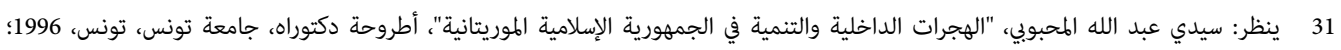

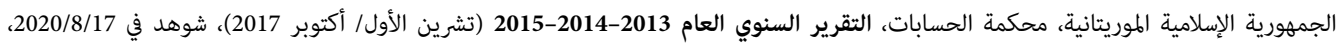

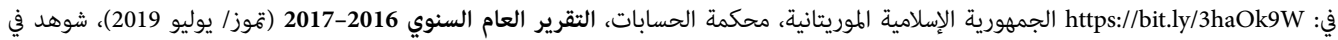
https://bit.ly/3kP5MmR في 2020/8/17

32

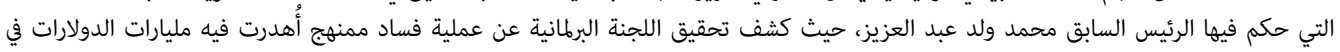

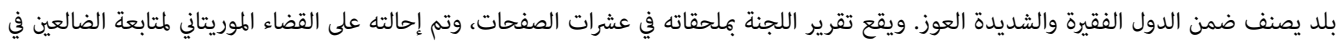

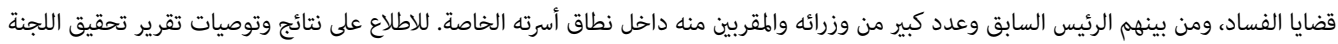

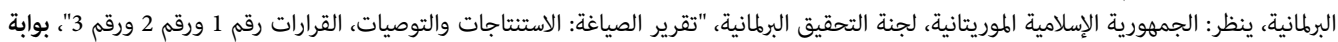
العلم، شوهد في 2020/8/15، في: https:/bit.ly/3aBRCAx 
وأنهت فترة الحكم المدني. ورافق هذا المعطى الارتهان لسياسات خارجية مسقطة، مثل سياسات الإصلاح الهيكلي التي فرضها البنك الدولي على الدول التي فشلت في تحقيق التنمية بمفردها.

فضلًا عن هذه المحدّدات الرئيسة في فهم تطور ظاهرة الفقر في موريتانيا، فإن السياق الاجتماعي فاقم من إشكال الفقر في المجتمع الموريتاني، بسبب التفاوتات الحادة، وملف الإرث الإنساني المرتبط بممارسة العبودية على فئات واسعة في المجتمع ما تزال إلى الآن تعاني مخلّفات تلك المهارسة، وتُمثّل بؤر الفقر الرئيسة داخل المدن والريف على حذّ سواء، وقد جعلت هذه الوضعية التعايش بين مكونات الشعب الموريتاني على المحك أكثر من مرّة. وفي الحصيلة، طاول الفقر أكثر من نصف المجتمع، بل لو أنّ خطوط الفقر خضعت مؤشرات أكثر موضوعية، واستجابة لمتطلبات العيش الكريم، لغطّى الفقر أكثر من ثلاثة أرباع المجتمع، وهو ما تثبته نسب الشعور بالفقر، بحسب آخر معطيات لمسوح الظروف المعيشية. والجدول (1) يبين تطور نسبة الفقر في موريتانيا منذ منتصف الثمانينيات حتى عام 2018.

\section{الجدول (1)}

خط الفقر في موريتانيا ونسبه والشعور به خلال الفترة 1987-2018

\begin{tabular}{|c|c|c|c|}
\hline 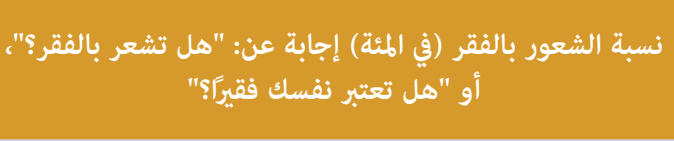 & فيبة الفقر & خط الفقر (سنويًًا) & السنة \\
\hline 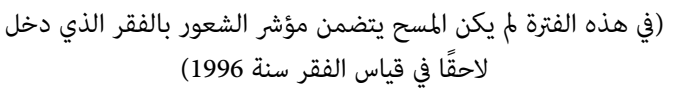 & 60 & $\begin{array}{c}\text { (نحو } 35000 \text { أوقيةًا) } \\
\text { دولارًا) }\end{array}$ & 1987 \\
\hline (م يكن المسح يتضمن مؤشر الشعور بالفقر) & 56.6 & 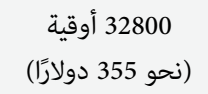 & 1990 \\
\hline 80.6 & 50.5 & $\begin{array}{c}\text { (نحو } 58400 \text { أوقيةًا) } \\
\text { دولارًا) }\end{array}$ & 1996 \\
\hline 82.2 & 46.3 & (نحو 490 دولارًا) & 2000 \\
\hline 81.2 & 46.7 & 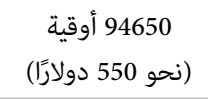 & 2008-2004 \\
\hline 80 & 42 & (نحو 129 ألف أوقية & 2018-2014 \\
\hline
\end{tabular}

المصدر: من إعداد الباحث استنادًا إلى: الإطار الاستراتيجي لمكافحة الفقر في موريتانيا، مج 2: خطة العمل 2011-2015 (نواكشوط: الوزارة الأولى، 2015). في ظل هذه الأرقام المخيفة عن مدى انتشار الفقر في المجتمع، عمدت الدولة إلى إعداد "الإطار الاستراتيجي لمكافحة الفقر" ليغطي الفترة 2000-2015 باعتباره المرجع الأوحد في مجال التنمية الاقتصادية والاجتماعية في موريتانيا. ويعين هذا الإطار هدفًا كبيرًا بمقتضاه تتراجع نسبة الفقر في عام 2015 إلى 25 في المئة. فها هي رهاناته 


\section{2. الفقر في ظل استراتيجية مكافحته الشاملة}

تُعرف الاستراتيجية الشاملة ككافحة الفقر في موريتانيا بـ "الإطار الاستراتيجي لمكافحة الفقر"، وقد أُعدت ضمن

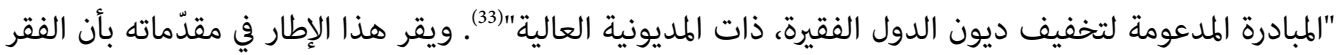
"يظل ظاهرة تبعث على القلق في موريتانيا، وتؤكد هذه الوضعية على ما يبدو أن مختلف الإجراءات والسياسات المطبقة، مل تفلح حتى الآن في تخليص بعض فئات السكان من دائرة الفقر"(34). وبما أن هذا الإطار يهدف في بعده الاستراتيجي إلى القضاء على الفقر، فإنه يؤكد البعد التشاركي في السياسات الموجهة لمكافحة الفقر، فيُعيّن دورًا بارزًا للقطاع الجمعياتي، الذي هو مدعوٌ، بحسب هذا الإطار، إلى "التشاور حول السياسات العمومية، والنهوض بثقافة النقاش الديمقراطي، والبناء والتنمية القاعدية وحماية المستهلك"(35)، في حين أن القطاع الخاص مدعوٌّ إلى "الإسهام في خلق مناصب الشغل والمشاريع، التي توظف أكبر قدر من الأيدي العاملة"، مع تركيز الدولة جهودها على "ضبط النشاط الاقتصادي والإثراف والتصميم وتنفيذ السياسات الاقتصادية واستراتيجيات التنمية، مع إيجاد مناخ ملائم لتطوير الفرص الاقتصادية"(36).كما ينطلق هذا الإطار من تشخيص لطبيعة الاقتصاد الموريتاني يرى أنّ له طابعين ربما

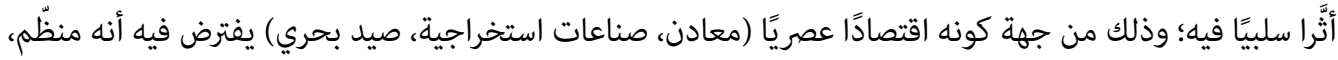
ويُحرّك النمو، ويرتبط إلى حد بعيد بالصادرات وله طابع غير توزيعي، ومن جهة كونه اقتصادًا إعاشيَّا يعتمد أساسًا على الزراعة المطرية وتنمية المواشي والصيد التقليدي الساحلي والقارّي، وهو لا يغطي احتياجات السكان في مجال الغذاء، ويمثل أهم أسباب الفقر في الريف(37).

وقد عيّن الإطار الاستراتيجي - في مرحلتيه الأولى والثانية - الترفيع في معدلات النمو الاقتصادي وسيلةً لمحاربة الفقر، وتقليص نسبته إلى حدود 25 في المئة. فالرؤية العامة للإطار تنطلق من أن "النمو الاقتصادي المطرد والمستدام، هو قوام أي تخفيف للفقر"(38. وقد كان الرهان في تحقيق مثل هذا النمو في المرحلة الأولى من الإطار على القطاع الأول، أي

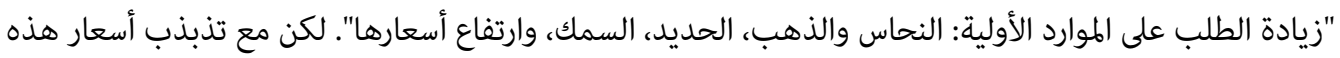
الموارد الأولية ودخول منافسين فيها مع السوق الموريتانية، تراجعت إسهاماتها في ميزان النمو؛ ما اضطر الدولة إلى رهان آخر لتحقيق النمو المطلوب، يتمثّل هذه المرة في قطاع الخدمات "النقل، المواصلات، التجارة، الفندقة، خدمات البنوك والتأمينات". لكن هذه العمليات والرهانات، إجمالًا، مل يكن الفقراء المستفيدين منها، فـ "النمو لا يتساقط في محيط الفقراء"، كما يدّعي أصحاب منطق السوق الحرة والاقتصاد الحر، بسبب عوامل الاختلال في توزيع عوائده. وهو ما تفطنت له الدولة في المرحلة الأخيرة من تقييم نتائج السياسة الاقتصادية والاجتماعية لـ "الإطار الاستراتيجي لكافحة الفقر". فـ "إنجاز نمو متسارع لا يكفي بالضرورة لتراجع الفقر، وذلك لسببين رئيسيين هما: 
^ كون قطاعات الاقتصاد الموريتاني - التي تعتبر المحركات الكلاسيكية للنمو - على ارتباط قوي بالعوامل الخارجية، ولا تؤثر سوى بقدر قليل في الفقراء.

† كون مناطق الفقراء والنشاطات الاقتصادية التي يعتمدها هؤلاء في معيشهم لا يكنها - نتيجة عدد من مكامن النقص الهيكلية - أن تستفيد من النمو الذي يتحقق بحكم معوقات هيكلية وتقنية وتنظيمية (39). إنّ السياسات القائة على محاربة الفقر بآلية النمو الاقتصادي تغفل عن أن المستفيد الأوحد من عائدات النمو هم

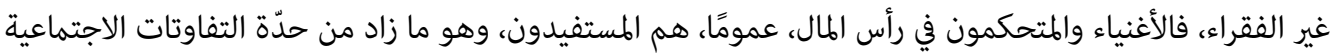

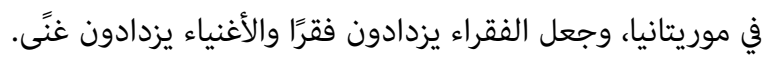

وأمام هذه الوضعية المحرجة، تم تعيين ثلاثة أهداف عاجلة لـ "الإطار الاستراتيجي لكافحة الفقر" في مرحلته

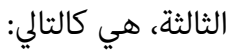
ه تقوية فاعلية الأنشطة المدرّة للدخل. 4 مواصلة تنفيذ البرنامج الوطني لدعم المقاولات الصغيرة.

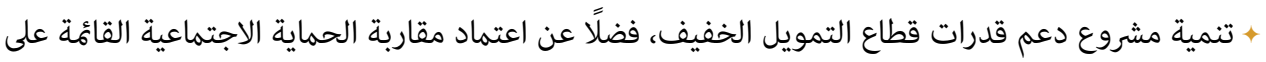
العمل الاجتماعي (توفير رعاية صحية وتعليمية للمجموعات الأكثر هشاشة) (40.). ومن اللافت للانتباه في هذه الخطة العاجلة بشأن تدارك خطر الفقر أن سياساتها هي، في إجمالها، السياسات نفسها التي يراهن عليها القطاع الجمعياتي، ويتخذها وسائل لكافحة الفقر. فكأن الدولة بذلك "تستسلم" أو تنقاد التهاد

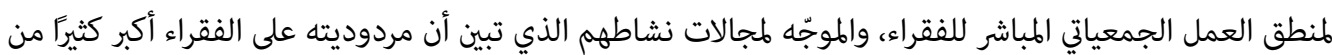

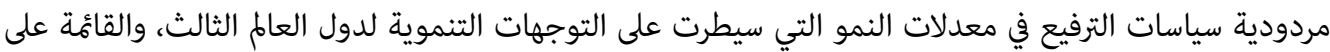

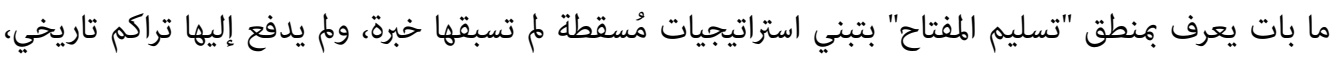

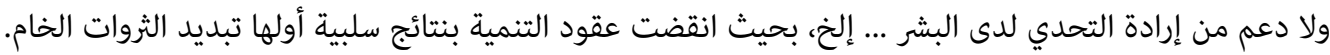
وثانيها سفه استهلاكي أتى على عوائدها. وهو ما حصل بالضبط في موريتانيا منذ الاستقلال حتى الآن. عجزت المقاربة الكلية لمكافحة الفقر عن تحقيق مطامحها، المتمثلة في تخفيض نسبة الفقر إلى 25 في المئة لأسباب

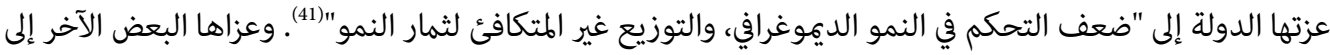
أسباب(42) عديدة تتمثل أساسًا في: الارتجالية وعدم الجدية في تنفيذ الخطط والبرامج التنموية، واتخاذ الفقر شعارًا

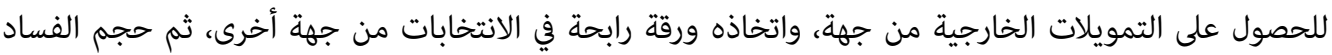

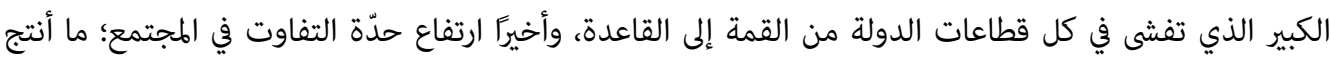
ظاهرتين متناقضتين، تتمثل أولاهما في طبقة ثرية متورّمة تسيطر - على الرغم من قلتها - على كافة دواليب الدولة وقطاعاتها، في مقابل غالبية فقيرة معدمة لا تتمكن من تلبية أبسط احتياجاتها الأساسية. 
وأمام هذه الوضعية المحرجة والخطيرة على الوضع الاجتماعي في البلد، بات من الضروري أن يتدخل فاعلون آخرون

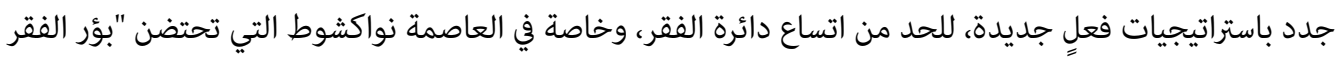
الخطيرة" اجتماعيًا. ويتعلق الأمر هنا أساسًا بالفاعل الجمعياتي الذي أصبحت أدواره تتعزز وتتعاظم أهميتها، وخاصة في العاصمة التي يتركز فيها معظم العمل الجمعياتي التنموي والخدمي والرئي الرعائي.

\section{ثالثًا: منهجية تناول إسهامم الجمعيات في مكافحة الفقر}

بالنظر إلى أن ظاهرة الفقر وظاهرة الجمعيات في موريتانيا تكتسي طابعًا مركّبًا من حيث المضامين والأبعاد، فإنها تتطلب أيضًا "منهجية مركّبة" تتضمن مجموعة من التقنيات التي طوّرتها العلوم الاجتماعية، مثل تقنية الملاحظة

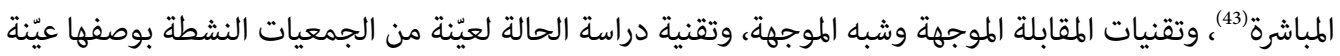

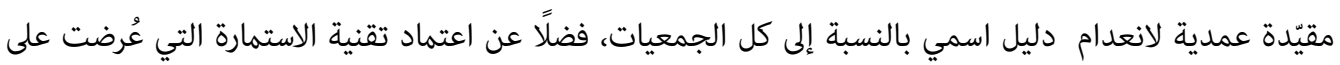

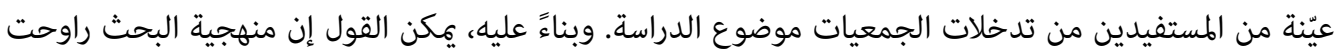

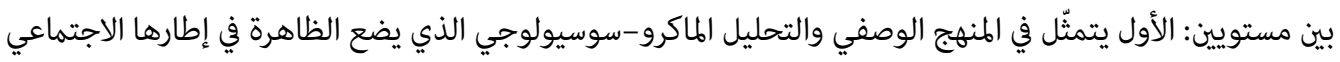

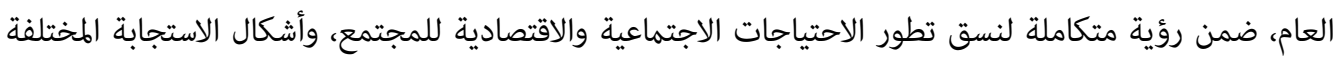

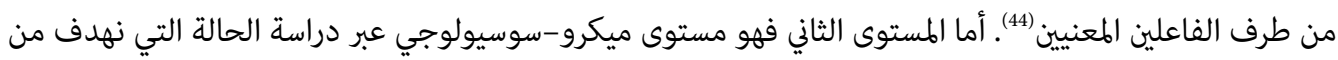
خلالها إلى معرفة نجاعة التدخلات التي تقوم بها الجمعيات في مكافحة الفقر.

وقد تم اختيار عيّنة البحث بحيث تكون عيّنة مقيّدة عمدية، وذلك لغياب دليل اسمي متكامل لكل الجمعيات والمستفيدين من تدخلاتها. وشملت العيّنة من جهة الجمعيات 5 جمعيات، وقد راعينا في اختيارها مجموعة

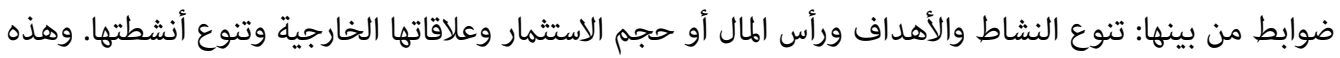

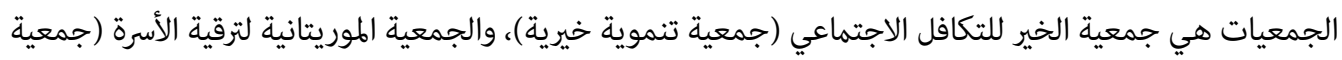

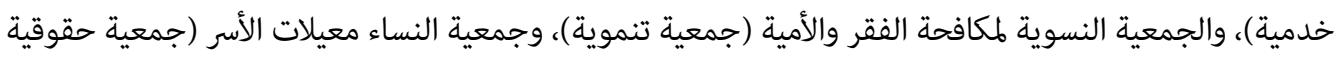
وتنموية بدرجة أقل)، وجمعية بسمة وأمل (جمعية تنموية وخدمية). أمّا عيّنة المستفيدين من تدخلات الجمات الجمعيات، فقد كانت ممثلة لمجتمع المستفيدين عمومًا، بحصيلة تصل إلى 119 فردًا مستفيدًا، من بينهم 51 فردًا يعيلون أسرًا صغيرة ومتوسطة الحجم.

\section{رابعًا: الجمعيات في موريتانيا: ما مدى فاعليتها في التخفيف من آثار الفقر؟}

تعتمد الجمعيات الموريتانية المعنيّة بكافحة الفقر، وبوجه خاص الجمعيات موضوع الدراسة، مجموعةً من

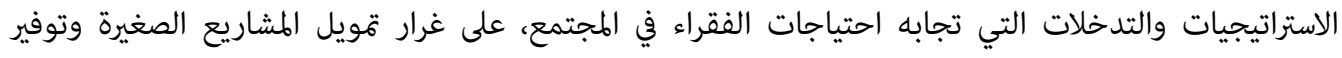

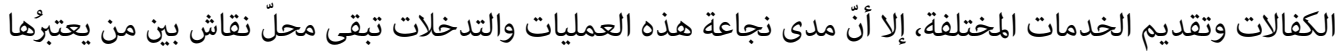

43 Henri Peretz, Les Méthodes en sociologie: L'observation (Paris: La Découverte, 2004), pp. 50-52.

44 فتحية السعيدي، "الجمعيات والمنظمات غير الحكومية وثقافة المجتمع المدني في تونس"، أطروحة دكتوراه، جامعة تونس، تونس، 2001، ص 23. 
نقطة التحول لتنمية بديلة خارج المؤسسات المعروفة (45)، والمعني هنا مؤسسات الدولة؛ فأنصار هذا الطرح يعتقدون

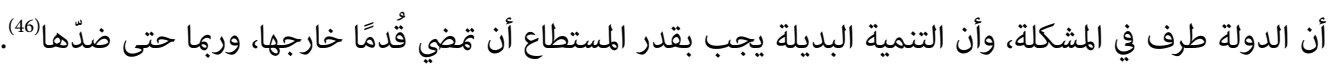

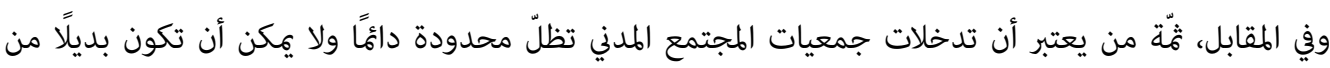

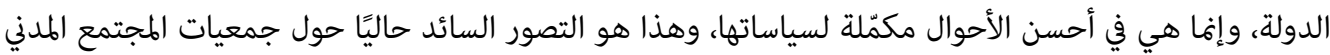
أو المنظمات غير الحكومية، وهي التسمية الرائجة لها اليوم. يُبيّن التحليل الأولي للمعطيات الأساسية لعيّنة الفقراء المستفيدين توزّعهم من حيث الفئات العمرية والمستوى التعليمي، ومن حيث نوع الاستفادة وشكلها.

(2) (2) (2) (2) (2) (2)

توزيع عيّنة المستفيدين بحسب فئاتهم العمرية

\begin{tabular}{|c|c|c|c|c|}
\hline (في المئة) & الكجموع & الإناث & الذكور & الفئة العمرية \\
\hline 35.29 & 42 & 22 & 20 & $1980-1960$ \\
\hline 21.84 & 26 & 20 & 6 & $2000-1981$ \\
\hline 42.85 & 51 & 28 & 23 & 2010-2001 \\
\hline \multirow[t]{2}{*}{100} & 119 & 70 & 49 & الهجموع \\
\hline & 100 & 58.82 & 41.17 & النسبة (في المئة) \\
\hline
\end{tabular}

المصدر: من إعداد الباحث، استنادًا إلى التحليل الأولي لمعطيات الدراسة الميدانية.

بالنظر إلى هذه التوزيعات، يتبين أن الفئة العمرية الأكثر هشاشة واستفادة من تدخلات الجمعيات هي الفئات العمرية المتوسطة، أي التي تنتمي، عمومًا، إلى فئة الشباب، وذلك بنسبة تناهز 63 في المئة. وتتكامل هذه النسبة

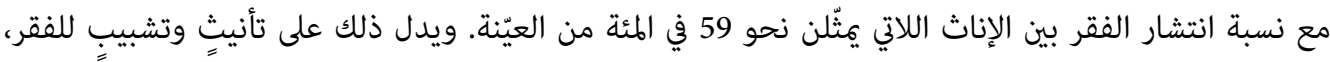
تدريجيًا، في المجتمع الموريتاني.

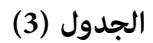

\section{توزيع عيّنة المستفيدين بحسب مستوياتهم التعليمية}

\begin{tabular}{|c|c|c|c|c|c|c|c|}
\hline الجنس & أميّ & قبل مدرسي & ابتدائي & إعدادي & ثانوي & جامعي & المجموع \\
\hline ذكور & 0 & 10 & 27 & 7 & 4 & 1 & 49 \\
\hline إناث & 15 & 11 & 21 & 11 & 10 & 2 & 70 \\
\hline المجموع & 15 & 21 & 48 & 18 & 14 & 3 & 119 \\
\hline (في النسبةة) & 12.6 & 17.64 & 40.33 & 15.12 & 11.76 & 2.52 & 100 \\
\hline
\end{tabular}

المصدر: المرجع نفسه. 
تكاد جميع الدراسات تُجمع على أهمية متغير التعليم في تفسير الأوضاع الاجتماعية بالنسبة إلى الفقراء الذين يتعرضون للتسرب المدرسي في فترة مبكرة من العمر بسبب ضغوط الحياة الاجتماعية، إلا أننا بدأنا نلاحظ تدريجيًا

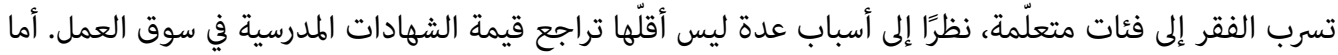

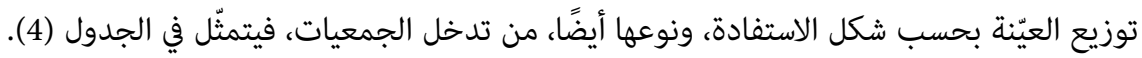

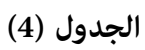

توزيع عيّنة المستفيدين بحسب شكل/ نوع استفادتهم من تدخّل الجمعيات

\begin{tabular}{|c|c|}
\hline 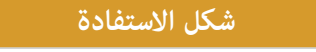 & عدد المستفيدين \\
\hline رعاية اجتماعية ومشاريع كفالة & 88 \\
\hline مشاريع مدرّة للدخل & 18 \\
\hline خدمات صحية وحقوقية & 13 \\
\hline الهجموع & 119 \\
\hline
\end{tabular}

المصدر: المرجع نفسه.

يقود هذا النمط من الإسهام والتدخل الجمعياتي إلى التطرق إلى مدى فاعليتها في التخفيف من آثار الفقر، وإلى

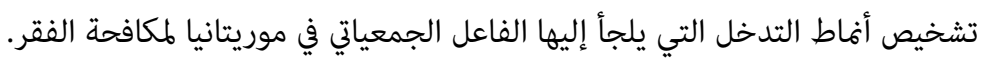

\section{1. الجمعيات في موريتانيا: الضرورة والوضع}

منذ عقدين من الزمن تقريبًا، عرفت الظاهرة الجمعياتية في موريتانيا تطورًا لافتًا للانتباه، حيث ارتفع عدد المنظمات والجمعيات غير الحكومية من 600 جمعية في عام 2000 إلى أكثر من 7 آلاف جمعية في عام

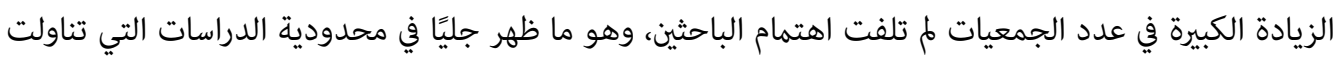
ظاهرة الجمعيات في موريتانيا (48).

بيد أن هذا التنامي الحاصل لعدد الجمعيات في موريتانيا ليس سمة خاصة بها وحدها، بل هو سمة عالمية لمسار

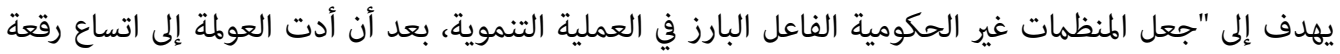
الفقر"(49)، وما استتبع ذلك من مخاطر تتعلق بالهجرة وتهديد الاستقرار الاجتماعي، وهو ما دفع الجهات المانحة

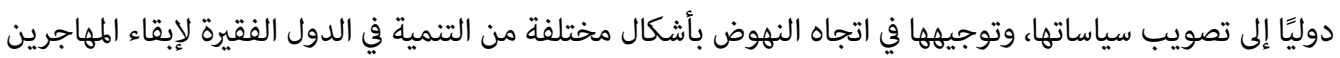

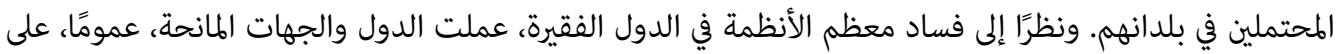
توجيه قطاع كبير من التمويلات لصالح المنظمات غير الحكومية، وهو ما زاد من وتيرة تشكيل الجمعيات، حتى

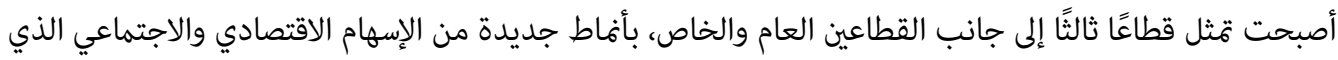
يُطلق عليه في بعض الأدبيات الاقتصاد الاجتماعي والتضامني غير الربحي القائم على فكرة التمكين (50). 47 مفوّضية حقوق الإنسان والعمل الإنساني والعلاقات بالمجتمع المدني، مقابلة شبه موجهة مع رئيس القطاع، نواكشوط، التهات 48 من أهم الدراسات التي اطلعت عليها، على قلّتها: ونّاس، الجمعيات في موريتانيا؛ عبد الله. 49 ع علي ليلة، دور المنظمات الأهلية في مكافحة الفقر (القاهرة: الشبكة العربية للمنظمات الأهلية، 
واعترافًا بأهمية الفاعل الجمعياتي في عملية التنمية الشاملة، خصّصت الأمم المتحدة دليلًا يتضمن معطيات وآليات إحصائية جديدة من أجل احتساب مساهمة الجمعيات والمؤسسات غير الربحية في الاقتصادات المحلية، وتوحيد آليات قياسها وتتبعها ومقارنتها على الصعيد الدولي (51).

وبالنسبة إلى موريتانيا، يكاد يتعذر منهجيًا وعمليًا فصل التاريخ الجمعياتي عن بنيته الاقتصادية والاجتماعية، وخاصة عن وضع البنية القبلية، "باعتبارها بنية تاريخية وعميقة ومتحكمة في مختلف مفاصل المجتمع وأنشطته وتعبيراته الرمزية والثقافية والمعيشية خاصة"(52). فالتعبيرات التطوعية والخيرية - التي هي سمات محددة للعمل الجمعياتي - بارزة في البناء المجتمعي التقليدي للمجتمع الموريتاني قبل قيام الدولة الوطنية بكثير. ففي المجتمع التقليدي الموريتاني، تبرز كل أشكال ملامح التضامن مع الضعفاء والفقراء، سواء عبر الأعطيات، أو تداول الأغذية، أو

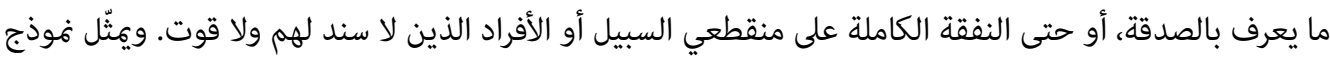
"المحظرة"(53) برهانًا على منطق التضامن وروح التطوع في المجتمع. فالمحظرة الموريتانية التي هي بمنزلة جامعة شعبية متنقلة (54)، لا يقتصر دورها على وظيفتها العلمية، بل إنه يشمل وظائف أخرى خيرية وتطوعية، لعل أبسط تعبيراتها تكفل المحظرة نفسها أو الحي أو القبيلة التي توجد بها بمأكل الطلاب ومشربهم ومسكنهم. كما تعتبر الحواضر والزوايا الصوفية شكلًا متميًزا من العمل الطوعي والخيري. فإضافةً إلى الوظائف الروحية التي تقوم بها

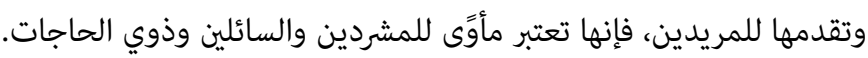

لكن هذه الأشكال والتعبيرات التطوعية والخيرية في المجتمع الموريتاني التقليدي التي لا يزال بعضها موجودًا، ظلت تستند إلى متغيرات العاطفة الدينية أو الانتماء القبلي، أي تلك المحددات التقليدية ضمن ما يسميه إميل دوركايم Emile Durkheim تعرّضت البنية الاجتماعية التقليدية لانسلاخات وتصدعات نتيجة مجموعة من التغيرات التي عرفها المجتمع الموريتاني من دخولٍ للاستعمار، وما اضطلع به من دور في تفكيك البنية الأميرية القبلية، ومن صراعاتٍ بين المجموعات مليكات القبلية والإمارات على الأراضي والمرعى وطرق التجارة، فضلًا عن الانتقال الفجائي من البداوة ونط عيشها إلى التحضر السريع بسبب الجفاف الذي ضرب البلاد في السبعينيات والثمانينيات، وما نجم عنه من تحطيم للبنية الاقتصادية التقليدية، وإثقالٍ لكاهل المناطق الحضرية الفتيّة، وإفشال للسياسات الاقتصادية والاجتماعية المتوالية ... إلخ. ومع كل هذه التغيرات والنقلات البنيوية Structural Transformation الجديرة بكل دراسة علمية (55)، أدّت هذه الانسلاخات والتصدعات إلى إفقار هذه البنية الاجتماعية، وجعلها عاجزة عن احتواء نسق الاحتياجات المتنامي في المجتمع أو الو

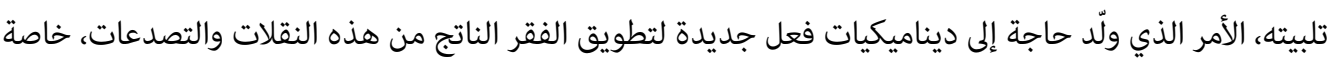

\section{1 بوخريص، ص 8. 52}

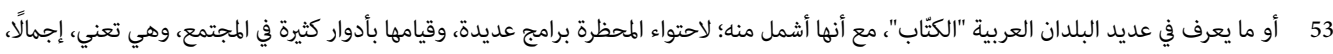

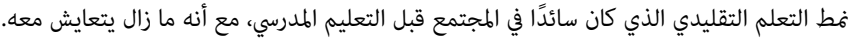

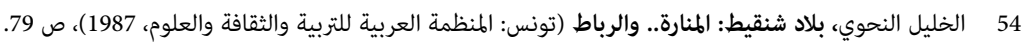
55 
مع عجز الدولة الناشئة حينها ومحدودية إمكاناتها وعدم قدرتها على تلبية كل الاحتياجات(56). ومن هنا، أصبحت

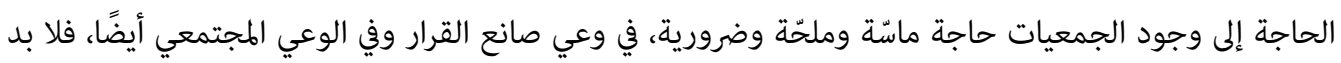

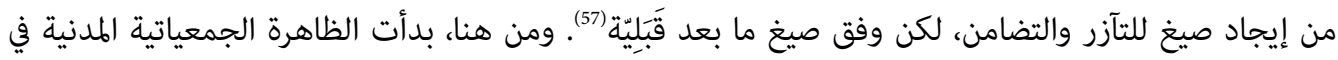

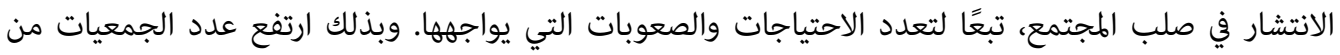
6 جمعيات عام 1969 إلى 600 جمعية عام 2000 وإلى 10 آلاف جمعية عام 2019. والفعل الجمعياتي في موريتانيا وتنوع، لكن بقي على رأس قائمة أهدافه هدف محاربة الفقر الذي يمثل التحدي الأكبر

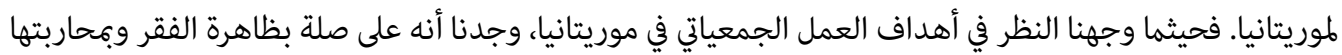
على وجه الخصوص. ويرى المنصف وناس، المتخصص في سوسيولوجيا، الجمعيات أن "تعدد الأنشطة وتنوعها يأتي تعبيرً عن ارتفاع حالة الفقر، والحاجة الماسة إلى دعم الجهود التنموية والصحية والتعليمية والخدماتية"(58). ومن خلال دراسة ميدانية لتدخلات 5 جمعيات لصالح عيّنة من الفقراء يصل عددها إلى 119 مستفيدًا، توصّلنا إلى النتائج التالية في مجال محاربة الجمعيّات للفقر، وقتثّل الفقراء لفقرهم ولتدخلات الجمعيات لصالحهم.

\section{2. علاقة الجمعيات موضوع الدراسة بالفقر}

تنطلق الجمعيات، موضوع الدراسة، في فهم علاقتها بالمجتمع، عمومًا، من مفاهيم التطوع والمسؤولية والواجب

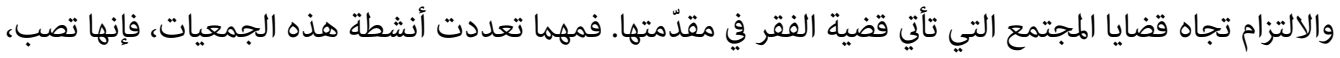

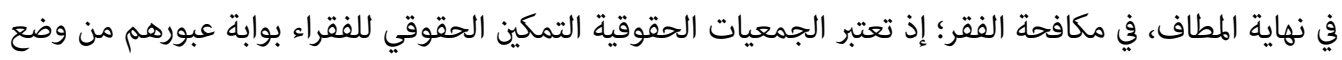
الحرمان والإقصاء إلى وضع التمتع بحقوقهم المدنية والاجتماعية والاقتصادية. فجمعية النساء معيلات الأسر، وهي

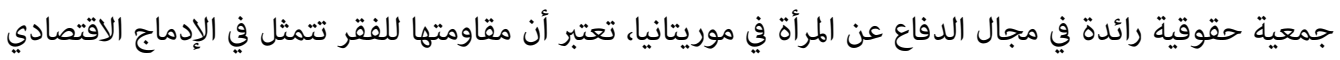

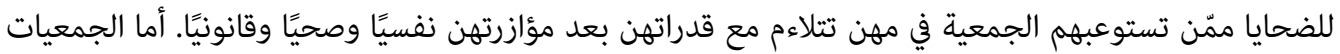

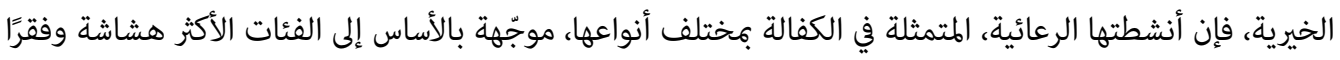
في المجتمع، كالأيتام والأرامل والأسر المعدمة. فجمعية مثل جمعية الخير للتكافل الاجتماعي في موريتانيا تتكفّل بـ 4 الأبه آلاف يتيم وأرملة و30 أسرة فقيرة. في حين تركز الجمعيات التنموية على تمويل أنشطة مدرّة للدخل لصالح الفقراء

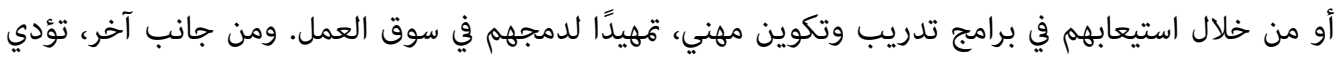
الجمعيات الخدمية أدوارًا مهمة على صعيد التثقيف الصحي والمدني وتوفير الرعاية الصحية للفقراء، وتعتبر الجمعية

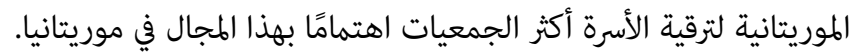

بالنظر إلى ما سبق، يمكن القول إن علاقة الجمعيات بالفقر هي علاقة متعددة المستويات؛ فمنها ما هو تنموي صرف، هما.

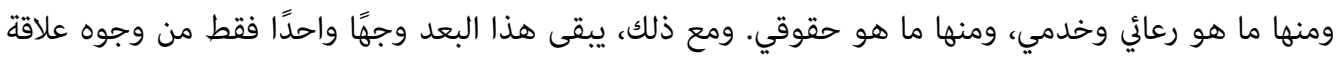

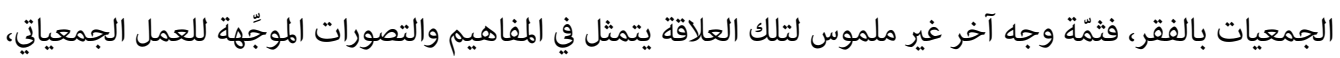
وعلى رأسها مفهوم التطوع والالتزام والتضحية، وهي معايير تعتبر أولوية بالنسبة إلى الجمعيات، وشرطًا أساسيًا في 
الانتساب، وهي ذاتها المعايير والمبادئ التي تُنشط العلاقة الاجتماعية بين الجمعية ومحيطها الاجتماعي التي تُعتبر استجابة لحاجاته وتعبيرً عن الالتزام بقضاياه؛ فالعمل الجمعياتي روح وتقليد وثقافة وصناعة وعي ومسؤولية (59).

\section{3. الإسهام الاقتصادي للفاعل الجمعياتي}

تتفاوت إنجازات الجمعيات موضوع الدراسة بحسب إمكاناتها المالية. فعلى سبيل المثال، أنجزت جمعية الخير للتكافل الاجتماعي 600 مشروع مدز للدخل لفائدة الأسر الفقيرة والشباب العاطلين عن العمل من أصحاب إنهاب الشهادات. وتشمل هذه المشاريع، بحسب البيانات التي اطلعنا عليها، محلات تجارية وورشات خياطة وبيع الملابس ومشاريع للتعاونيات النسوية ... إلخ. وإلى جانب ذلك، أنجزت الجمعية 4 آلاف كفالة تشمل صرف مخصصات شهرية وبطاقة صحية للعلاج وتوفير الحقائب المدرسية ومرشدات اجتماعيات لكل مجموعة من الأيتام المكفولين، إلى جانب كفالات أخرى تتمتع بها 50 أسرة و30 طالبًا من طلبة التعليم العالي الذين يدرسون خارج موريتانيا. وفي الجانب الإغاثي، أنجزت الجمعية 30 منشأة مائية في تجمعات فقيرة داخل الأرياف الموريتانية.

وفي السياق ذاته، تشير المعطيات الخاصة بالجمعية الموريتانية لترقية الأسرة إلى إنجاز عدد من المشاريع، أبرزها إنشاء

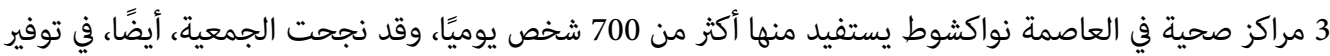

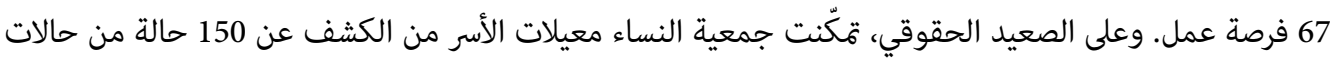
الرق، وقد استطاعت الجمعية من خلال مساندتها القانونية للضحايا من تحرير هؤلاء العبيد، وجمعهم بشتات

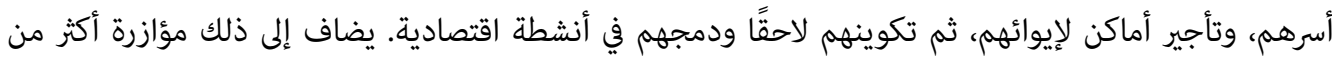

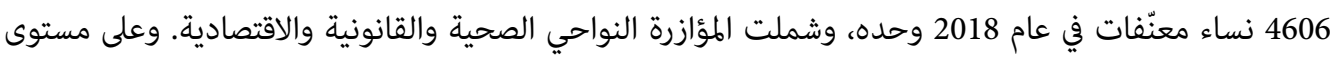
المشاريع المدرّة للدخل، أنشأت جمعية النساء معيلات الأسر 1800 تعاونية نسوية على مستوى ولايات الداخل الموريتاني، و3 اتحاديات تعاونية على مستوى العاصمة نواكشوط تضم أكثر من 580 تعاونية نسوية.

هذه عيّنة منتقاة من الإسهامات والتدخلات التي يقوم بها الفاعل الجمعياتي في موريتانيا، والتي يتبين مدى ملامستها لاحتياجات الفئات الهشة والفقيرة اجتماعيًا، وفضلًا عن كونها تدخلات عينيّة، فإنها تأخذ مع الزمن شكل علاقة مئل اجتماعية بين الجمعية وجمهور المستفيدين من تدخلاتها؛ ذلك أن الجمعية تبقى على صلة بالمستفيدين منها، ويصل متوسط تلك العلاقة في بعض الأحيان إلى 10 سنوات، خاصة في مشاريع الكفالة، والمشاريع المدرّة للدخل التي تتواصل على أمد متوسط أي 5 سنوات فأكثر.

إلا أن التحديد الأدق لإسهام الجمعيات الاقتصادي يتطلّب معطيات تشمل المؤشرات المتعارف عليها في قياس إسهام الجمعيات الاقتصادي. ومن أهم هذه المؤشرات قيمة المشاريع التي يسيرها هذا القطاع من خلال حجم الميزانيات ومستوى الاستثمار وتوفير فرص العمل وأعداد المستفيدين والمتطوعين والأعضاء في الجمعية. ويُبين الجدول (5)

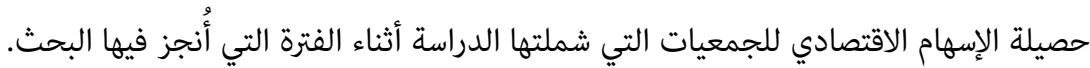




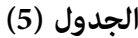

\section{مؤشرات الإسهام الاقتصادي للجمعيات موضوع الدراسة}

\begin{tabular}{|c|c|c|c|}
\hline |عدد المتطوعين والأعضاء في & والاسثمارات الميزانية & 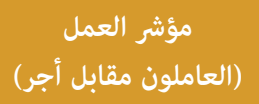 & الجمعية \\
\hline 74 & 1.2 مليون دولار & 54 & جمعية الخير للتكافل الاجتماعي في \\
\hline 605 & 277 ألف دولار & 67 & الجمعية الموريتانية لترقية الأسرة \\
\hline 10879 & 259 ألف دولار & 68 & جمعية النساء معيلات الأسر \\
\hline 76 & 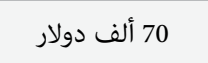 & 24 & الجمعية النسوية لكافحة الفقر والأمية \\
\hline 80 & 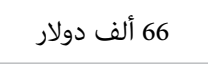 & 4 & 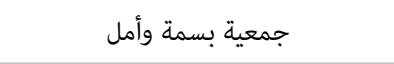 \\
\hline 11741 & 1.877 مليون دولار & 217 & المجموع \\
\hline
\end{tabular}

المصدر: من إعداد الباحث، استنادًا إلى نتائج الدراسة الميدانية.

يتبين من الجدول أن حجم ميزانية الجمعيات التي شملتها الدراسة واستثماراتها يناهز مليونَي دولار سنويًا، ويعتبر

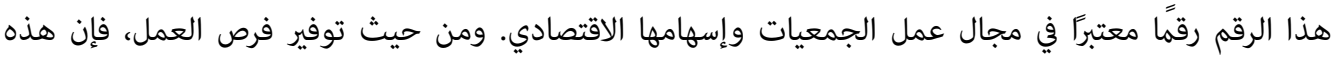

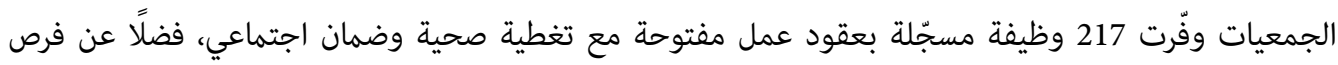
العمل الموسمية عند إنجاز مشاريع إنشائية؛ على غرار بناء الوحدات السكنية، أو القيام بحملات صحية وخدمية. كما

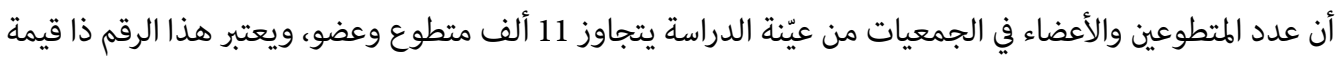

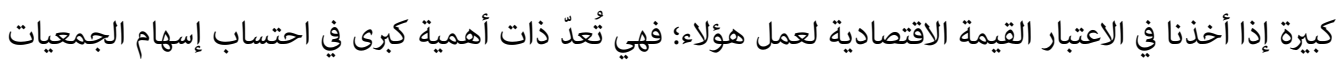
الاقتصادي، كما أن هذا الرقم مؤشر إيجابي على مستوى تجنيد وإدارة المورد البشري لصالح العمل التطوعي.

\section{4. تقييم عمل الجمعيات في مكافحة الفقر عبر عيّنة من المستفيدين من تدخلاتها} عمدنا، لتقييم دور الجمعيّات محل الدراسة في مقاومة الفقر، إلى اختيار عيّنة من المستفيدين من هذه الجمعيات، من

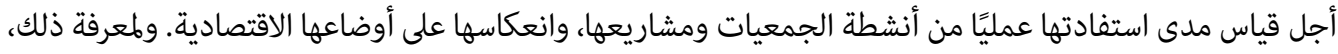

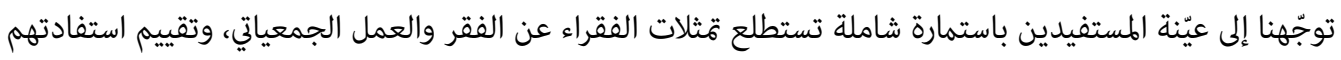

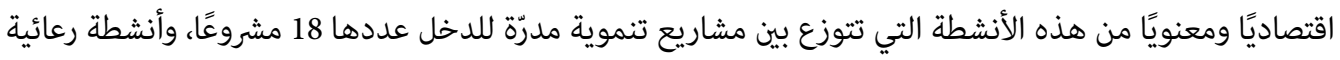

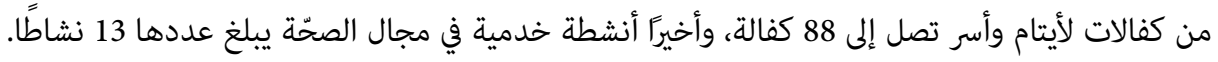

\section{أ. تمثلات العيّنة بشأن الفقر}

تُعتبر قتثلات الفقراء عن فقرهم وتفسيرهم له ولأسبابه أمرًا مهمًا بالنسبة إلى بحثنا، وذلك من عدة أوجه؛ أولها معرفة

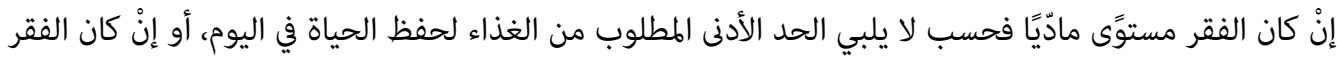

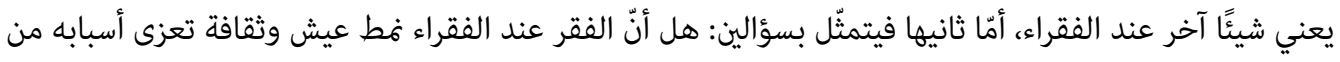

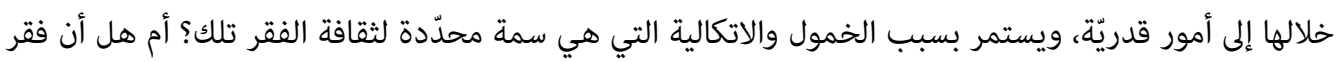


الفقراء مردّه عدم تكينهم من الوسائل والإمكانات التي تخوّلهم الخروج من دائرة الفقر؟ وأمّا ثالثها، فهو حسم هذه الإثكاليات في ضوء فشل، أو نجاح، تدخلات الجمعيات التي تُعنى بالفقراء عبر العمليات التمكينية التي تستهدفهم

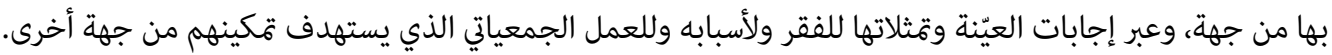
إجابةً عن السؤال: من هو الفقير في نظرك؟ تبيّن، من خلال نتائج تفريغ الاستمارة، أن أغلبية أفراد العيّنة يعتبرون

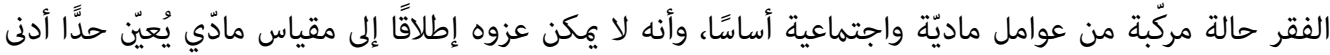

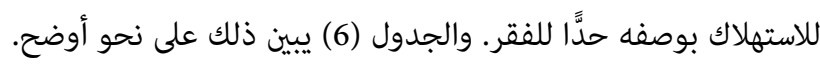

الجدول (6)

التمثلات المتصلة بتعريف "الفقير" لدى أفراد العينة

\begin{tabular}{|c|c|c|c|c|c|c|c|c|}
\hline \multicolumn{8}{|c|}{ المستوي التعليمي } & \multirow[b]{2}{*}{ ق مثثل الفقر } \\
\hline (في النسية) & المجموع & جامعي & ثانوي & إعدادي & ابتدائي & محظري & أميّ & \\
\hline 84.88 & 101 & 3 & 14 & 18 & 40 & 16 & 10 & 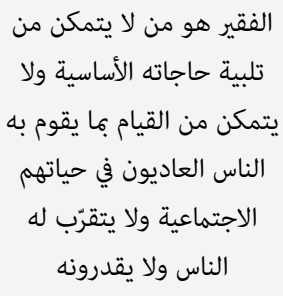 \\
\hline 15.12 & 18 & 0 & 0 & 0 & 8 & 5 & 5 & 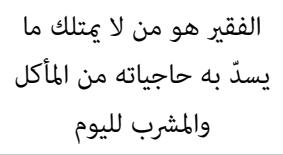 \\
\hline 100 & 119 & 3 & 14 & 18 & 48 & 21 & 15 & المجموع \\
\hline & 100 & 2.5 & 11.76 & 15.12 & 40.38 & 17.64 & 12.6 & النسبة (في المئة) \\
\hline
\end{tabular}

المصدر: المرجع نفسه.

على الرغم من تباين المستويات التعليمية بين فقراء العيّنة، وانتماء معظمهم إلى مستويات تعليمية "متدنيّة"، فإن تمثلهم المتعلق بالفقر هو تمثل مركّب، لا يُختصر في بعد واحد ماتين مادّي، بل يشمل الأبعاد الاجتماعية الأخرى التي هي ذات أولوية بالنسبة إلى عيّنة البحث. وضمن التحليل الكيفي لمضمون المقابلات مع المستفيدين، تكرّر عدة مرّات مفهوم "الإحراج الاجتماعي"، بوصفه مفهومًا وصفيًا يصفون به حالة فقرهم، وهو أبرز دليل على حضور البعد الاجتماعي في تحديد الفقر.

إن الفقير في نظر العيّنة هو من يمتلك دخلًا متدنيًا لا يمكّنه من تلبية احتياجاته الأساسية، ولا يمكنه أيضًا من القيام

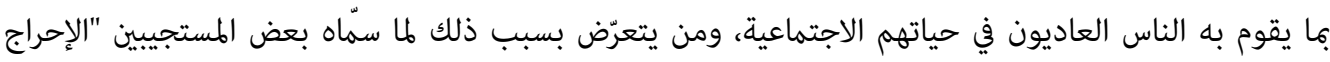

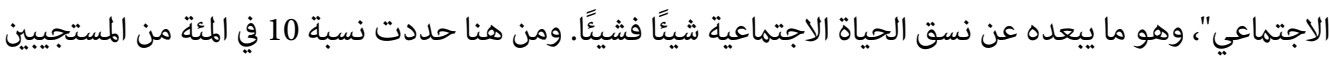

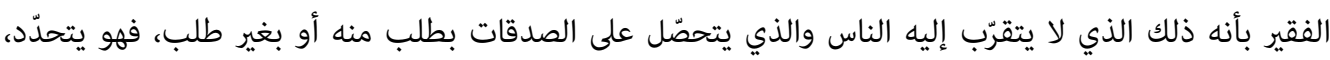


شاء أم كره، ضمن مجال الاستبعاد والإقصاء الاجتماعيين. كما وردت في العيّنة عدّة تعبيرات دالّة على وضع الفقير،

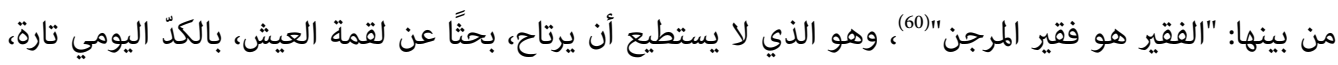

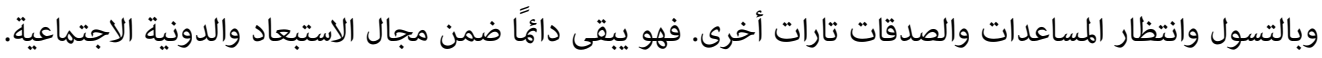
وضمن استبعاد لقولة ثقافة الفقر في تفسير وضع الفقراء وأسباب فقرهم، تبيّن لنا من خلال تفريغ نتائج الاستمارة

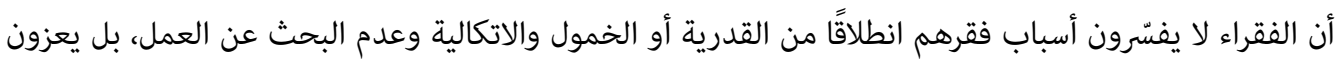

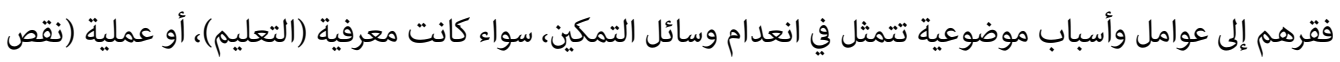

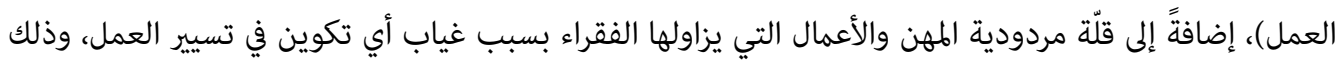

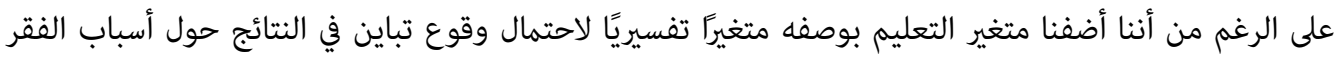
عند الفقراء. والجدول (7) يبين ذلك.

\section{الجدول (7)}

\section{تمثلات لأسباب الفقر عند الفقراء}

\begin{tabular}{|c|c|c|c|c|c|c|c|c|}
\hline \multicolumn{8}{|c|}{ المستوى التعليمي } & \multirow[b]{2}{*}{ أسباب الفقر عند الفقراء } \\
\hline 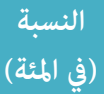 & ألمجموع & جامعي & ثانوي & إعدادي & ابتدائي & محظري & أميّ & \\
\hline 1.68 & 2 & 0 & 1 & 0 & 0 & 0 & 1 & القضاء والقدر \\
\hline 47.90 & 57 & 0 & 1 & 10 & 22 & 10 & 14 & نقص التعليم \\
\hline 43.70 & 52 & 3 & 8 & 4 & 26 & 11 & 0 & نقص العمل \\
\hline 1.68 & 2 & 0 & 2 & 0 & 0 & 0 & 0 & عدم البحث عن العمل \\
\hline 5.04 & 6 & 0 & 2 & 4 & 0 & 0 & 0 & عدم المساواة \\
\hline 0 & 0 & 0 & 0 & 0 & 0 & 0 & 0 & الاتكالية والخمول بين الفقراء \\
\hline 100 & 119 & 3 & 14 & 18 & 48 & 21 & 15 & المجموع \\
\hline
\end{tabular}

المصدر: المرجع نفسه.

تبين هذه التوزيعات أن مردّ أسباب الفقر عند الفقراء ليست أسبابًا قدرية، ولا نتيجةً لاتكالية وعدم بحث عن

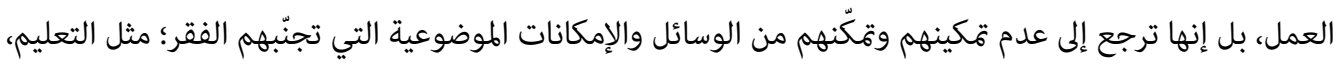

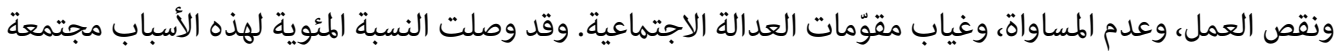

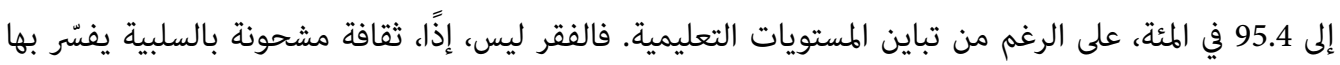

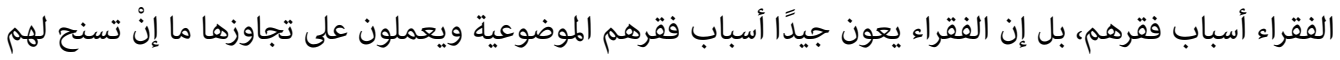

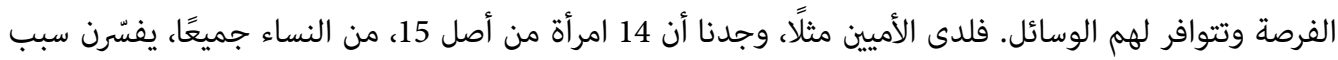

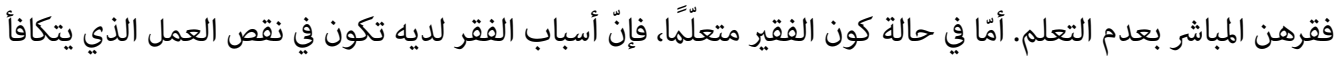

مع مؤهلاته التعليمية. 
ولم نكتفِ بهذا المستوى في تمثلات الفقراء عن الفقر، بل تجاوزنا ذلك إلى معرفة ما إذا كان الفقراء يعملون أم لا يعملون بحسب فقراء العيّنة، وقد وجدنا أن الفقراء، عمومًا، وفقراء العيّنة خصوصًا، يُقدّرون العمل، ويعتبرونه

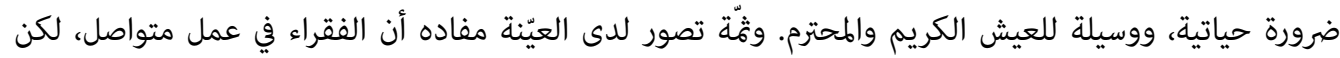

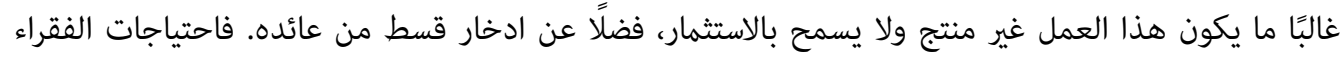
اليومية ضاغطة إلى درجة تجعلهم عاجزين عن تلبية احتياجاتهم واحتياجات أسرهم الأساسية، خاصّة في مجال

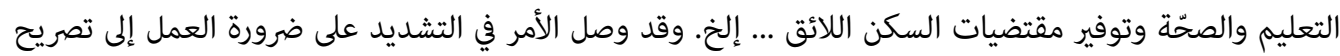
بعض أفراد العيّنة بأن "الفقير هو الميّت" أو هو المحروم الذي لا يتمكن من العمل لأسباب صحيّة وبدنيّة. فالعمل هو الأولوية الأولى لدى الفقراء وهاجسهم الدائم الذي يطاردونه يوميًا ويبحثون عنه، بغض النئ النظر النمر عن كونهم رجالًا أو نساء.

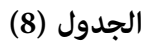

تمثلات الإجابة عن الفقراء: يعملون أم لا يعملون؟ - مت

\begin{tabular}{|c|c|c|c|}
\hline المجموع & الفقراء يعملون & الفقراء لا يعملون ومتكلون & 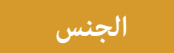 \\
\hline 70 & 87.15 في المئة من كل الإناث & 12.85 في المئة من كل الإناث & إناث \\
\hline 49 & 100 في المئة من كل الذكور & 0.00 في امئة من كل الذكور & ذكور \\
\hline 119 & 110 & 9 & المجموع \\
\hline 100 & 92.43 & 7.57 & النسبة (في المئة) \\
\hline
\end{tabular}

المصدر: المرجع نفسه.

من الملاحظ أن الرأي المتمثّل بأنّ الفقراء لا يعملون ومتكلون يرجع كله إلى نساءٍ وذلك بنسبة 12.85 في المئة فقط من مجموع النساء، وهو ما يمكن تفسيره بأنّ أغلب الفقيرات في موريتانيا نساءٌ. فبالنظر إلى هيمنة العقلية التقليدية

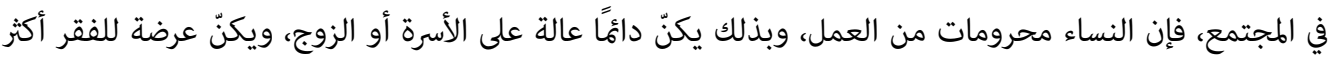

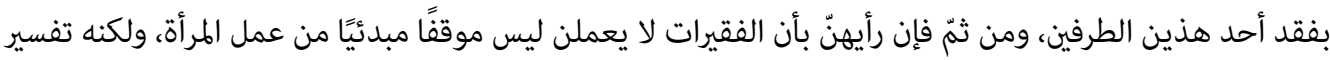

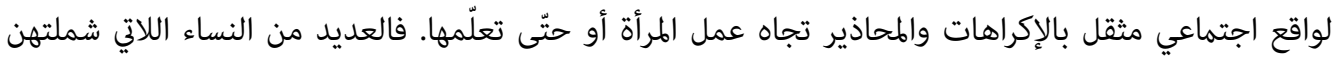

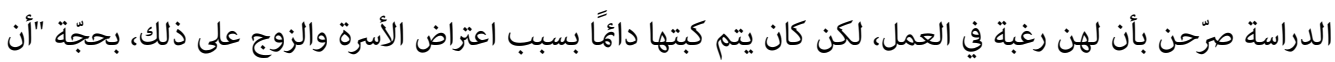

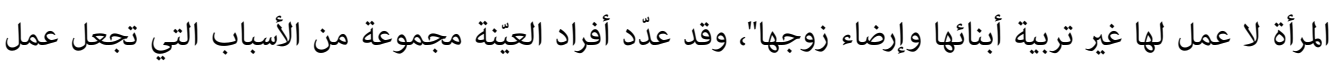
الفقراء غيرَ مُسهِمِ في الحدّ من فقرهم، من بينها ما يلي:

ه عمل الفقراء غالبًا ما يكون في مهن حرفية وعضلية ضعيفة المردود تكاد لا تكفي لسد الاحتياجات الأساسية. ه حجم الأسر التي يعيلها الفقراء غالبًا ما يكون كبيرًا، ما يجعل الدخل موجهًا إلى الاحتياجات اليومية. ه عدم سماح الزوج لزوجته بأن تعمل لأنه يرى في عملها "وصمة عار اجتماعية عليه"، فهو وحده المطالب بالعمل و إعالة الأسرة. 
كما أن أولويات الفقراء ومشاكلهم تعكسان حاجة ملحّة وتوقًا إلى التمكن من الوسائل الموضوعية لتغيير أوضاعهم، حيث تأتي احتياجات توفير تعليم الأبناء على رأس أولويّاتهم، وذلك بغض النظر عن التباينات والفروق القائمة في المستويات التعليمية لأفراد العيّنة. والجدول (9) يوضح أهم مشاكل عيّنة الدراسة وأولويّاتها.

(9) الجدول)

تمثلات لأهم مشاكل الفقراء لدى أفراد العينة وأولوياتهم

\begin{tabular}{|c|c|c|c|c|c|c|c|c|}
\hline \multicolumn{8}{|c|}{ المستوى التعليمي } & \multirow[b]{2}{*}{ المشاكل والأولويات } \\
\hline (النسبة الفئة) & ( & 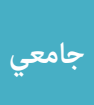 & ثانوي & إعدادي & 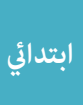 & محظري & 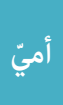 & \\
\hline 68.9 & 82 & 2 & 10 & 12 & 33 & 15 & 10 & مشاكل التعليم وتوفير احتياجاته \\
\hline 9.25 & 11 & 0 & 4 & 2 & 2 & 2 & 1 & مشاكل الفقر المدقع وتدني الدخل \\
\hline 10.08 & 12 & 1 & 0 & 0 & 7 & 2 & 2 & مشاكل السكن \\
\hline 11.77 & 14 & & 0 & 4 & 6 & 2 & 2 & مشاكل تتعلق بكثرة المصاريف \\
\hline 100 & 119 & 3 & 14 & 18 & 48 & 21 & 15 & المجموع \\
\hline
\end{tabular}

بحسب هذه التوزيعات، تتمثّل الأولوية، التي تمثل مشكلًا أساسيًا وهاجسًا، بالنسبة إلى فقراء العيّنة، في التعليم والرعاية الصحية. ففقراء العيّنة حريصون كل الحرص على توفير التعليم الأفضل لأبنائهم، في حالة كونهم أسرًا،

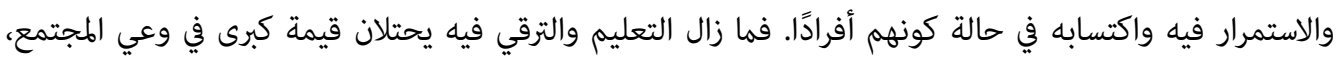

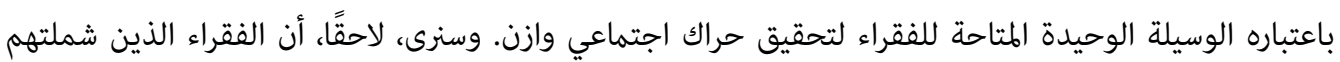
الدراسة، يوجهون معظم عائد المشاريع والكفالات إلى تحسين المستويات التعليمية لأبنائهم؛ ذلك أن متابعة تعليم الابن، أو الابنة، هي الاستثمار الكبير بالنسبة إلى الأسرة الفقيرة المعدمة من وسائل تحقيق الحراك الاجتماعين المعتويات الثقيل بالزبونية والمحسوبية والوجاهة الاجتماعية والولاء السياسي ... إلخ. وفي مستوَى ثانٍ من مستويات مشاكل الفقراء

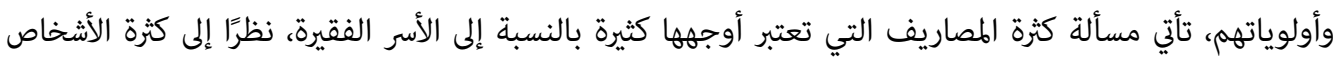
الذين تحويهم وتعيلهم؛ فما زالت الأسرة الموريتانية أسرة ممتدة، يتعايش فيها، إضافة إلى الزوجين والأطفال المباشرين، الإخوة والأخوات وبعض الأقارب وآباء الزوجين أيضًا، وهو ما يضاعف من تكاليف الأسرة التي غالبًا ما تكون منوطة بشخص واحد فيها. وفي مستوى ثالث من مستويات احتياجات ومشاكل العيّنة، يأتي مشكل السكن،

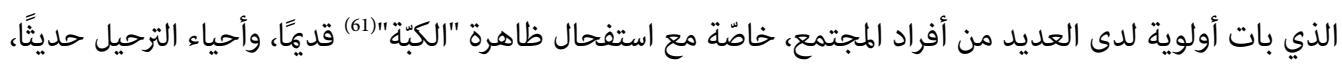
وهي أحياء صفيحية، في أغلب الأحيان، تفتقد إلى أبسط مقوّمات السكن الضرورية. وفي آخر المشاكل، تأتي المشاكل 
تالمتعلقة بحالة الفقر المدقع المرافق لتدني الدخل. ولعل السبب في أن تكون هذه المشكلة هي المشكل الأخير في سلّم ترتيب أولويات ومشاكل أفراد العيّنة هو الاستفادة من تدخلات الجمعيات.

\section{ب. تمثلات المستفيدين من الجمعيات للعمل الجمعياتي}

الصورة السائدة عن الجمعيات في موريتانيا هي صورة سلبية جدَّا، وذلك نظرًا إلى ما ارتبطت به الجمعية، في مخيال

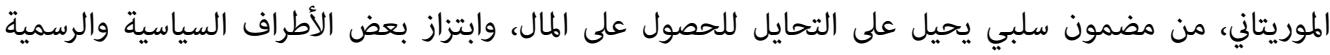

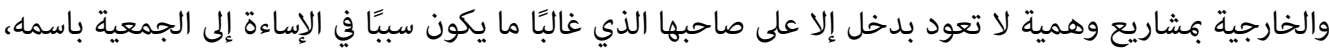

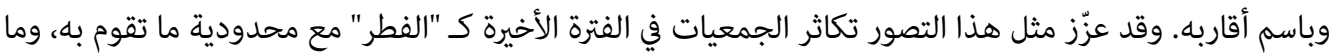
هو موجود منها بالفعل على أرض الواقع ويمارس عملًا تنمويًا أو خدميًا حقيقيًا. من هذا المنطلق، أردنا أن نتعرض لتمثلات عيّنة الدراسة للجمعيات، والجمعيات التي تجري الاستفادة منها على

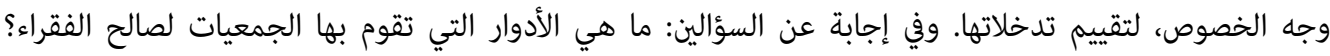

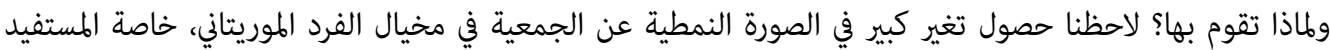

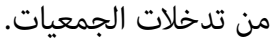

الجدول (10)

تمثلات المستفيدين لعمل الجمعيات وأدوارها وغاياتها

\begin{tabular}{|c|c|c|c|c|c|c|c|}
\hline \multicolumn{7}{|c|}{ المستوى التعليمي } & \multirow{2}{*}{ ما الذي تقوم به الجمعيات؟ ومات مبرّاته؟ } \\
\hline الكجموع & جامعي & ثانويّ & إعداديّ & ابتدائي" & محظري & أميّ & \\
\hline 34 & 0 & 13 & 1 & 12 & 6 & 2 & تقديم المساعدة إلى المحتاجين \\
\hline 32 & 0 & 1 & 2 & 10 & 7 & 12 & فعل الخير والتصدق على الفقراء \\
\hline 51 & 3 & 0 & 15 & 24 & 8 & 1 & تككين الفقراء بتنمية مواردهم وتأهيلهم وتدريبهم \\
\hline 2 & 0 & 0 & 0 & 2 & 0 & 0 & القيام بأنشطة شكلية بغرض الحصول \\
\hline 119 & 3 & 14 & 18 & 48 & 21 & 15 & 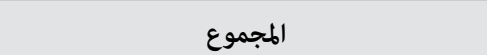 \\
\hline
\end{tabular}

المصدر: المرجع نفسه.

يبدو أن ثَّة وعيًا متزايدًا بأهمية أنشطة الجمعيات بالنسبة إلى الفقراء في العيّنة، وخاصّة أنشطتها التمكينية بنسبة

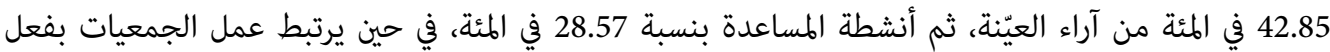

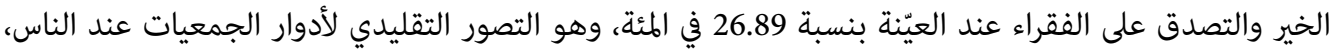

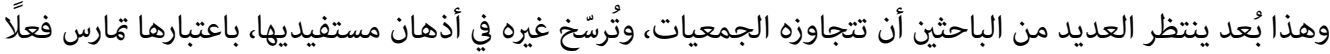

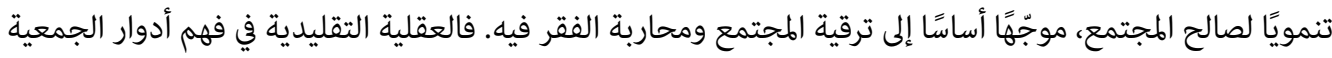
تحمل وعيًا سلبيًا يتصوّر بمقتضاه الأفراد والمستفيدون من الجمعيات، نرجيه خاصّة أن الجمعية هي بنك خيري يعطي 
من دون أن يتابع ويقيّم، ما يولّد عقلية الاستغلالية والاتكالية لدى العديد من الفقراء المستفيدين من الجمعيات.

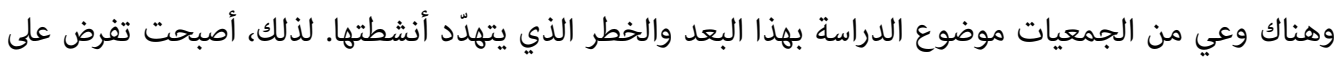

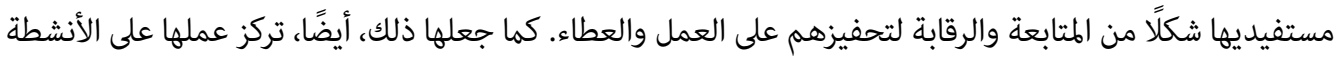
والتدخلات ذات الطابع التمكيني، كالتدريب والتكوين والتعليم والتأهيل وقويل الأنشطة المدرّة للدخل، في ظل التزامات وعقود ورقابة تجعل المستفيد يتوجّه إلى العمل بدلًا من التعويل على سخاء الجمعية.

وفي مستوى آخر من مستويات تمثل المستفيدين لعمل الجمعيات، تطرّقنا إلى ما ينبغي أن تقوم به الجمعيات

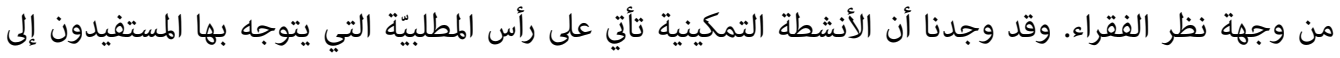

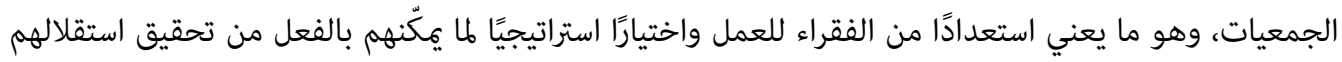

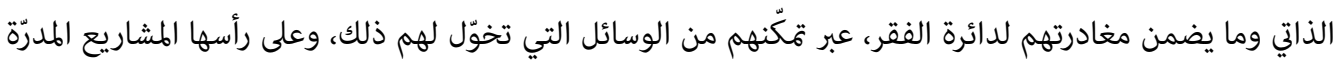
للدخل، والتدريب والتكوين المتعلقين بحرف معيّنة ذات طلب في السوق.

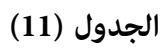

تمثلات المستفيدين لعمليات التمكين المفترض أن تقوم بها الجمعيات

\begin{tabular}{|c|c|c|c|c|c|}
\hline \multicolumn{5}{|c|}{ عمليات التمكين التي يرى الفقراء المستفيدون أنها الأنسب لكافحة الفقر } & \multirow[b]{2}{*}{ الجنس } \\
\hline (في النسية) & المجموع & التمويل والكفالة & كفالة الأيتام & قمويل مشاريع للدخل & \\
\hline 41.17 & 49 & 19 & 10 & 20 & ذكور \\
\hline 58.83 & 70 & 40 & 11 & 19 & إناث \\
\hline 100 & 119 & 59 & 21 & 39 & الهجموع \\
\hline 100 & & 49.57 & 17.65 & 32.77 & النسبة (في المئة) \\
\hline
\end{tabular}

المصدر: المرجع نفسه.

ينطلق من يُؤيّدون المشروع المموّل والكفالة معًا من تجربة مفادها أنّ من استفادوا من هذين التدخلين معًا تمكّنوا

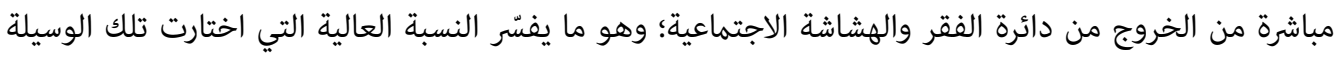
49.57 في المئة، في حين ينطلق من يرون خيار تمويل المشاريع والتكوين من مقولة وردت على لسان عدة مستفيدين،

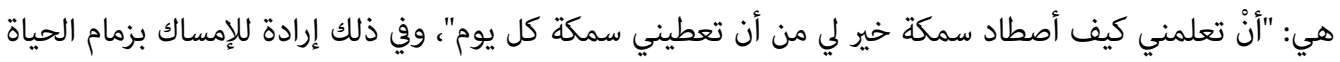
و إدارتها. فالتمكين من الوسائل هو أفضل وأقصر طريق لكافحة الفقر بحسب هؤلاء، وذلك بنسبة عالية وصلت إلى

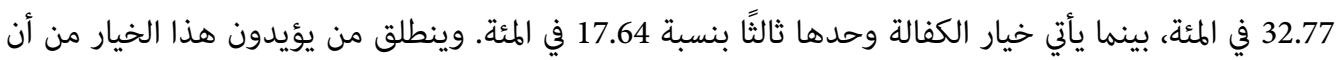
الأيتام والأرامل شريحة واسعة في المجتمع وشريحة هشّة جدًّا، والكفالة عامل أساسي في تنمية وبناء هذه الشريحة ومساعدتها، وخاصّة الأطفال في مسارهم التعليمي؛ فكلّما كانت الكفالة شاملة ومستمرة، كانت احتمالات نجاحهم في مسارهم التعليمي أكبر وأكثر إمكانًا. 


\section{خاتمة}

حاولنا من خلال هذه الدراسة أن نسهم، ولو بقدر قليل، في توفير تصور علمي عن تعامل الجمعيات موضوع

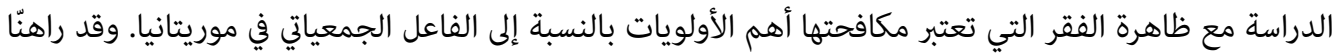

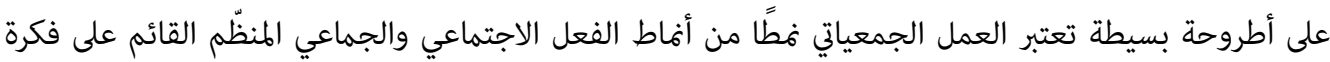

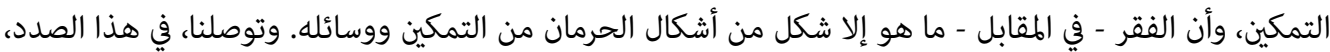
إلى أن توافر معطيات الوظائفية في عمل الجمعيات مع تبني فكرة تمكين الفقراء من خلال مشاريع تنموية أو رعائية

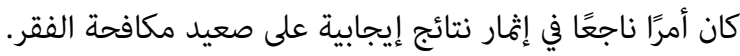

فأمام "الإخفاق الحكومي" في تطويق الفقر ومظاهره، بات من الضروري إفساح المجال أمام فاعلين جدد للتدخل من

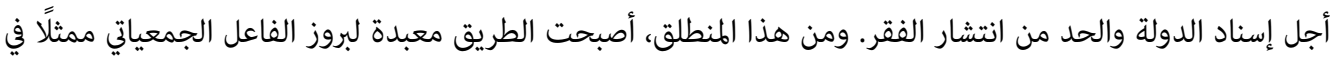

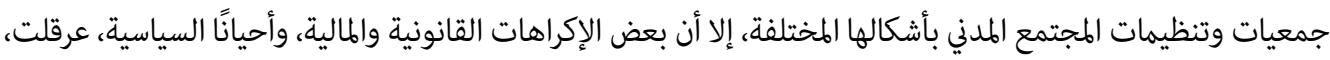

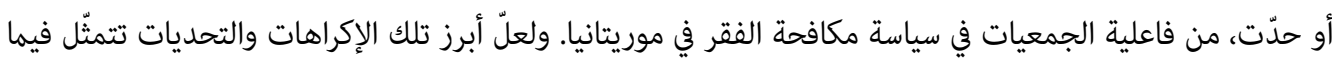

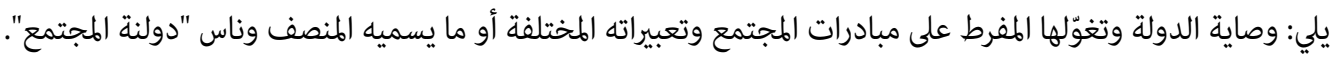
فعلى الرغم من الانفتاح الذي عرفته موريتانيا مع دستور 1991 الذي أطلق الحريات، وتبنّي الدولة لعقيدة المشاركة

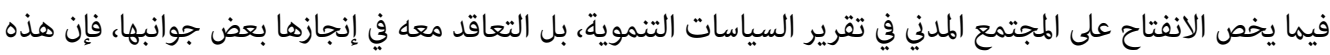

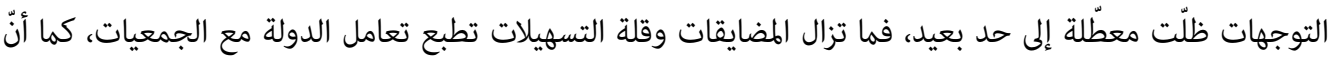
الانتقائية تسيطر على سلوك الدولة في التعامل مع التمويلات المخصصة للعمل الجمعياتي، الأمر الذي يساهم في إفراغ بعض التكتلات الجمعياتية من مضمونها، وذلك بتحولها إلى أداة بيد السلطة، وتحوّلها إلى واجهة للفساد المهاد المالي الجمعياتي. وفي الجانب الآخر، تنطوي ممارسة العمل الجمعياتي في موريتانيا على مجموعة من الاختلالات التي جعلت

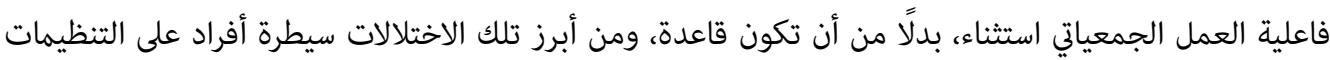

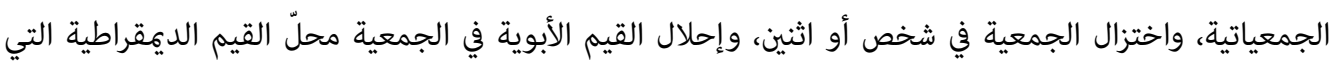

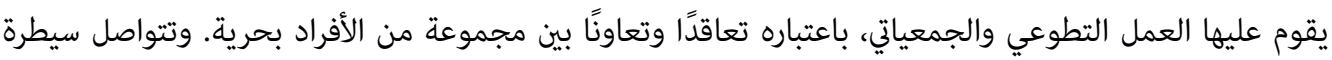

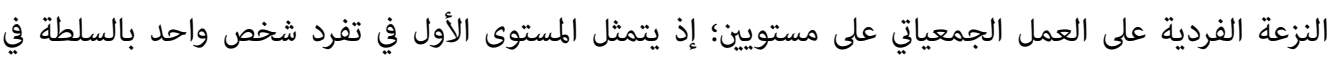

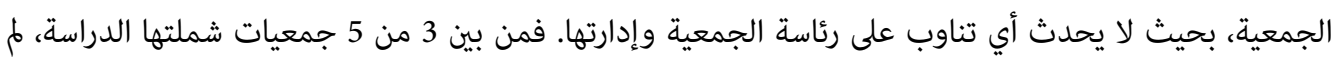

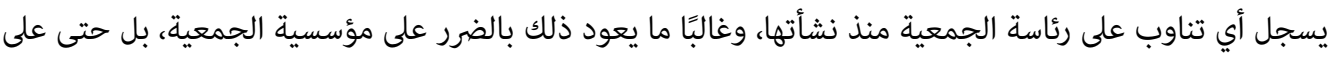

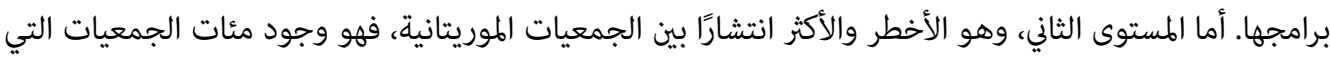
يقتصر وجودها على وجود شخص واحد هو المكتب التنفيذي للجمعية والناطق باسمها، ويُصطلح على تسمية هذه وهنه الظاهرة محليًا بظاهرة جمعيات "الكراطيبل"، أي جمعيات المحفظة المتنقلة التي يسخّرها أصحابُها للتربح وتحصيل المال، وهو الأمر الذي أضرّ كثيرًا بسمعة العمل الجمعياتي في موريتانيا.

فضلًا عن البعد السابق، ثَّة أيضًا بعد آخر معوّق في عمل الجمعيات الموريتانية يتمثل في مستوى حضورها في

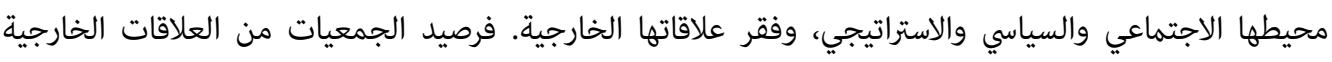
وبالجهات الممولة ما يزال في حدوده الدنيا، وهو ما يفسر إلى حد ما محدودية تدخلات الجمعيات؛ ومن ثمّ يمكن إكن 
القول إن حداثة التجربة الجمعياتية في موريتانيا ما زالت تلقي بظلالها على العمل الجمعياتي. ولذلك، فإنّ الجمعيات الموريتانية الجادة مدعوة إلى الاعتناء بهذا الجانب لتطوير مستوى كفاءتها و إمكاناتها.

على الرغم من تلك العوائق، تبيّن لنا من خلال دراسة ميدانية معمّقة أن الفاعل الجمعياتي، مع حداثة تجربته،

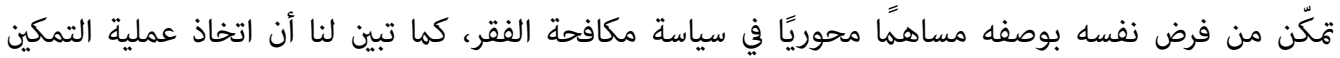

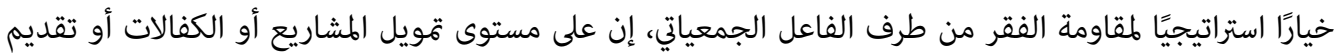

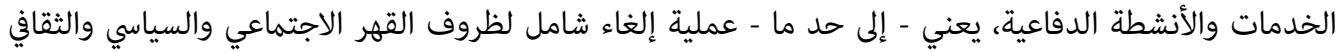

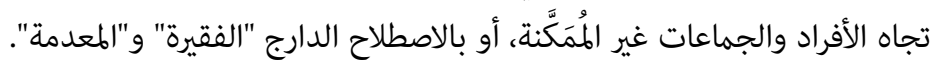

ولذلك، فإن خيار تمكين الفقراء، عبر إشراكهم في العملية التنموية وإعطائهم زمام المبادرة في إدارة مشاريعهم الخاصة

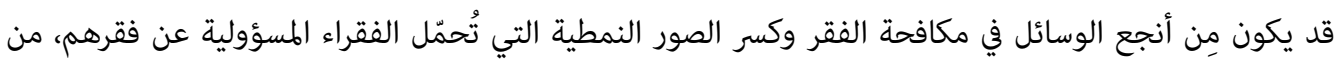
خلال اتهامهم بالكسل والخمول، على غرار ما تروّجه نظرية ثقافة الفقر التي تقع على النقيض من نظريات تقكين الفقراء التي تقدّم منظورًا بديلًا في سياسات التنمية.

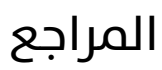

العربية

الإطار الاستراتيجي لكافحة الفقر في موريتانيا: حصيلة 2006-2010. نواكشوط: الوزارة الأولى، 2010. الإطار الاستراتيجي لكافحة الفقر في موريتانيا: خطة عمل 2011-2015. نواكشوط: الوزارة الأولى، 2015. بوخريص، فوزي. مدخل إلى سوسيولوجيا الجمعيات. الدار البيضاء: أفريقيا الشرق، 2013.

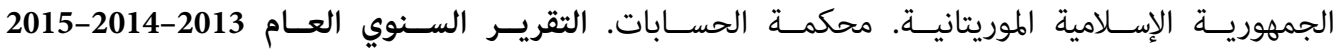

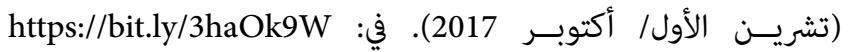

https://bit.ly/3kP5MmR التقرير العام السنوي 2016-2017 (توز/ يوليو 2019). في:

الجمهورية الإسلامية الموريتانية. لجنة التحقيق البرطانية. "تقرير الصياغة: الاستنتاجات والتوصيات، القرارات رقم 1 ورقم 2 ورقم 3". بوابة العلم. في: https:/bit.ly/3aBRCAx

دي ساشيه، فرانسيس. موريتانيا من سنة 1900 إلى سنة 1975. ترجمة محمد بن بوعليبة بن الغراب. نواكشوط: جسور للنشر، 2013.

السعيدي، فتحية. "الجمعيات والمنظمات غير الحكومية وثقافة المجتمع المدني في تونس". أطروحة دكتوراه. جامعة تونس. تونس.

عبد الله، منّينة. التقرير السنوي الأول: نشاط المنظمات الأهلية في الجمهورية الإسلامية الموريتانية. القاهرة: الشبكة العربية للمنظمات الأهلية، 2002. 
غدنز، أنتوني. علم الاجتماع. ترجمة فايز الصياغ. بيروت: المنظمة العربية للترجمة، 2005.

فريدمان، جون. التمكين: سياسة التنمية البديلة. ترجمة ربيع وهبة. القاهرة: المركز القومي للترجمة، 2011. قيرة، إسماعيل. "من هم فقراء الحضر؟ قاع المدينة العربية فهوذجًا". المستقبل العربي. العدد 205 (آذار/ مارس 1996). ليلة، علي. دور المنظمات الأهلية في مكافحة الفقر. القاهرة: الشبكة العربية للمنظمات الأهلية، 2002. المجلس الوزاري للشؤون الاجتماعية في جامعة الدول العربية ولجنة الأمم المتحدة الاقتصادية والاجتماعية لغربي

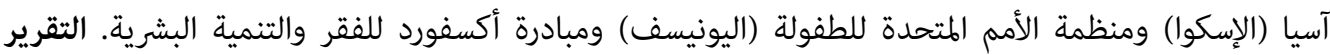

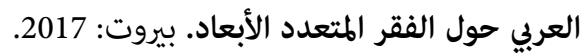

المحبوبي. سيدي عبد الله. "الهجرات الداخلية والتنمية في الجمهورية الإسلامية الموريتانية". أطروحة دكتوراه. جامعة تونس. تونس، 1996.

النحوي، الخليل. بلاد شنقيط: المنارة.. والرباط. تونس: المنظمة العربية للتربية والثقافة والعلوم، 1987. ونّاس، المنصف. الحياة الجمعياتية في المغرب العربي: التاريخ والواقع والآفاق: الجزائر، المغرب الأقصى، تونس. تونس: ألتالير، 1997.

. الجمعيات في موريتانيا: التاريخ والتشريع والأنشطة: دراسة ميدانية. غير منشورة (2002).

ويبستر، أندرو. مدخل لسوسيولوجية التنمية. ترجمة حمدي حميد يوسف. سلسلة المائة كتاب. بغداد: دار الشؤون الثقافية العامة، 1986.

\section{الأجنبية}

Bonte, Pierre. "L'évolution de la société rurale Mauritanienne: Le pari de la sécurité alimentaire." Politique Africaine. no. 55. (Octobre 1994).

Boukraa, Ridha. Comprendre la mondialisation: Études sociologiques. Tunis: Centre de Publication Universitaire, 2005.

Labbens, Jean. Sociologie de la Pauvreté: Le tiers monde et le quart monde. Paris: Gallimard, 1978. Laroussi, Houda. Micro-crédit et lien social en Tunisie: La solidarité instituée. Tunis: IRMC; Paris: Karthala, 2009.

Lewis, Oscar. Five Families: Mexican Case Studies in the Culture of Poverty. New York: Basic Books, 1959.

Peretz, Henri. Les méthodes en sociologie: L'observation. Paris: La Découverte, 2004.

Sumpf, Joseph \& Michel Hugues. Dictionnaire de sociologie. Paris: Librairie Larousse, 1973. 